Linköping Studies in Science and Technology

Dissertation No. 1619

\title{
Oxidation and Corrosion of New MCrAlX Coatings - Modelling and Experiments
}

\section{Kang Yuan}

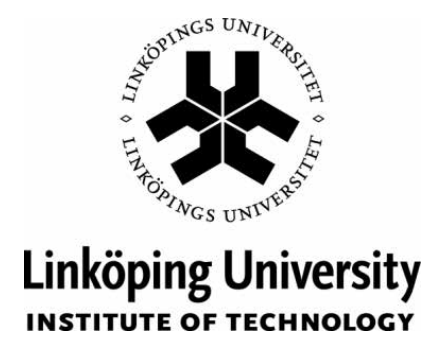

Division of Engineering Materials, Department of Management and Engineering Linköping University, 581 83, Linköping, Sweden

http://www.liu.se

Linköping, September 2014 
Dissertation opponent: Professor Dr Robert Vaßen, from Forschungszentrum Jülich GmBh, Institut für Energie- und Klimaforschung, Germany.

Defend date: October 30, 2014

Place: ACAS, Hus A, Campus Valla, Linköping Univeristy, Linköping

Cover:

Front: Cross-sectional morphology of a MCrAlY coating on superalloy, showing microstructure after a high-temperature oxidation (the image height is $191 \mu \mathrm{m}$ ). Back: The profiles of alloying elements in a MCrAlY coating-superalloy system after a high-temperature oxidation (the solid curves are simulation results, and the dots are experimental ones).

Printed by:

LiU-Tryck, Linköping, Sweden, 2014

ISBN: 978-91-7519-247-5

ISSN 0345-7524

Distributed by:

Linköping University

Department of Management and Engineering

SE-581 83, Linköping, Sweden

(C) 2014 Kang Yuan

No part of this publication may be reproduced or transmitted in any form without prior permission of the author. 


\section{Abstract}

MCrAlY coatings ("M" for $\mathrm{Ni}$ and/or $\mathrm{Co}$ ) are widely used for the protection of superalloy components operated at high temperatures such as in the hot sections of gas turbines. The exposure to high temperature can cause coating degradation due to oxidation or hot corrosion at the coating surface. Microstructures in the coating and the coating life are affected also by the diffusion of alloying elements through the coating-superalloy interface. This $\mathrm{PhD}$ project, by applying thermodynamic modelling and experimental tests, investigates the oxidation and hot corrosion behavior of new MCrAIX coatings, in which X, referring to minor elements, is used to highlight the functions of such elements.

In order to understand and predict the coating degradation progress during thermal exposure, an oxidation-diffusion model has been established for MCrAlX coating-superalloy systems, which integrates the oxidation of aluminum at coating surface, diffusion of alloying elements, and the diffusion-blocking effect in the materials. The predicted chemical composition profile and microstructure agreed well with experimental results in a CoNiCrAlYSiTa-Inconel 792 system. The model was further applied in several coating-superalloy systems to study the influence of coating composition, superalloy composition and temperature on the evolution of microstructure in the coating and the coating life. The results have demonstrated the potential of the model in designing new durable MCrAlX coatings. In addition to the applications in coating-superalloy systems, the model was also adapted for studying the microstructural development in a superalloy in which internal oxidation and nitridation occurred in an oxidation process.

The oxidation behavior of some HVOF MCrAlX coatings was studied by thermal exposure at different temperatures $\left(900,1000,1100{ }^{\circ} \mathrm{C}\right)$. Different spinels formed above the alumina scale, depending on the oxidation temperature. The minor alloying elements, Ru and Ir, had no direct influence on the oxidation behavior but may affect the phase stability in the coating.

MCrAlX coatings were also tested in 48-hour cycles at $900{ }^{\circ} \mathrm{C}$ in different hot corrosion environments containing sulphates and/or $\mathrm{SO}_{2}$. The results showed that the coating performance was dependent on coating quality, concentration of $\mathrm{Al}$ and $\mathrm{Cr}$ in the coating, and the hot corrosion condition. It was also found that the addition of $\mathrm{SO}_{2}$ in the environment may not necessarily be bad for hot corrosion resistance of some MCrAlY coatings. 


\section{Acknowledgement}

Grateful acknowledgment is to Siemens Industrial Turbomachinery AB, Swedish Energy Agency through KME consortium - ELFORSK for the financial supports in the four-year project (2010 to 2014). The AGORA MATERIA and Strategic Faculty Grant AFM in Linköping University are also acknowledged for supporting my research and study in Linköping University. I'd like also to greatly thank China Scholarship Council who provided the scholarship for me during my study in Sweden.

\section{To my supervisors and colleagues:}

I greatly thank my supervisors. My main supervisor Ru Lin Peng put so much effort to guide my research, and also helped me a lot especially at the beginning of my study and living in Linköping. Xin-Hai Li also put a lot of effort in my $\mathrm{PhD}$ research, helping me to gain not only academic knowledge but also industry experience in the field. Sten Johansson was the only supervisor of mine who can not speak Chinese (not his fault), but helped me a lot on how to do a good research. Yan-Dong Wang was my abecedarian in the field of material science when I was in college in China, and, furthermore, he was the person who recommended me to come to Linköping University for my $\mathrm{PhD}$ study in 2010.

I also want to thank all my colleagues in the division of Engineering Materials (IEI, Linköping University) for their friendship, encouragement and support in my $\mathrm{PhD}$ study. I'd like to especially thank Robert Eriksson with whom I had the opportunity to create several papers during my PhD study. And I hope I will have more cooperation with many of my colleagues in my future research. 


\section{To my families and Chinese friends:}

I am always grateful to my father and mother who gave the birth to me and raised me up till now. I also feel very lucky to have a two-year younger brother with whom I had a wonderful time during childhood. Now he becomes a good friend. They, my families, are always the greatest driving force of my striving in life.

I also want to thank my girlfriend $\mathrm{Xu} Z$ Zhenyuan who is like an angel to me such that I want to share my life with in the future (I am quite sure of this). With her, I have the opportunity to share all my happiness and emotions, opinions on life and family, and many other things but not on my particular scientific research (she thought it was boring).

I'd like to thank my Chinese friends in Sweden: Wei Shuoguo, Chen Zhe, Zhang Ying, Xu Yixuan, Chen Lujie, Wang Daqing, Zhang Lihua, Zhang Ya, Liu Linn, Zhu Jianqiang, and many others. They shared a lot happy time with me in weekends or in Red Days here, like having parties, BBQs, movie nights, picnics, out-door sports, travelling, hiking, and so on. In particular, I'd like to thank Shuoguo and Zhe, who had many interests the same as mine, like sports, photography and travelling. I really enjoyed sharing the apartment with these two guys.

\section{To Sweden (for fun):}

I also enjoyed the springs and summers in Sweden (it is true), but not the long and dark winters which drove me to make the decision to go back to my country - China after the $\mathrm{PhD}$ carrier. 


\section{List of papers}

The thesis is based on the following papers:

I. K. Yuan, R. Eriksson, R. Lin Peng, X.-H. Li, S. Johansson, Y.-D. Wang, Modeling of microstructural evolution and lifetime prediction of MCrAlY coatings on nickel based superalloys during high temperature oxidation, Surface and Coatings Technology. 232 (2013) 204-215.

II. K. Yuan, R. Eriksson, R. Lin Peng, X.-H. Li, S. Johansson, Y.-D. Wang, MCrAlY coating design based on oxidation-diffusion modelling. Part I: Microstructural evolution, Surface and Coatings Technology. 254 (2014) 79-96.

III. R. Eriksson, K. Yuan, X.-H. Li, R. Lin Peng, MCrAlY coating design based on oxidation-diffusion modelling. Part II: Lifing aspects, Surface and Coatings Technology. 253 (2014) 27-37.

IV. K. Yuan, R. Lin Peng, X.-H. Li, S. Johansson, Y.-D. Wang, Simulation of oxidationnitridation-induced microstructural degradation in a cracked Ni-based superalloy at high temperature, MATEC Web of Conferences. 14 (2014) 16004-p.1-p.6.

V. K. Yuan, R. Lin Peng, X.-H. Li, S. Johansson, Y.-D. Wang, Some aspects of elemental behaviour in HVOF MCrAlY coatings in high-temperature oxidation. Submitted to Surface and Coatings Technology.

VI. K. Yuan, R. Lin Peng, X.-H. Li, S. Johansson, Y.-D. Wang, Hot corrosion behavior of MCrAlY coatings containing Ru and Ir, Submitted to Surface and Coatings Technology.

VII. K. Yuan, R. Lin Peng, X.-H. Li, S. Johansson, Y.-D. Wang, Hot corrosion of MCrAlY coatings in sulphate and $\mathrm{SO}_{2}$ environment at $900{ }^{\circ} \mathrm{C}$ : is $\mathrm{SO}_{2}$ necessarily bad? Surface and Coatings Technology (under review). 


\section{Abbreviations}

\begin{tabular}{|c|c|}
\hline APS & atmospheric plasma spray \\
\hline $\mathrm{BC}$ & bond coat \\
\hline $\mathrm{BCC}$ & body centered cubic \\
\hline BLZ & $\boldsymbol{\beta}$-left zone \\
\hline BSE & backscattered electron \\
\hline CSI & coating-substrate interface \\
\hline DBTT & ductile-to-brittle transition temperature \\
\hline EB-PVD & electron beam physical vapour deposition \\
\hline EBSD & electron backscatter diffraction \\
\hline EDS & energy dispersive spectroscopy \\
\hline FCC & face centered cubic \\
\hline HVOF & high-velocity oxy-fuel \\
\hline IBDZ & inner- $\boldsymbol{\beta}$-depletion zone \\
\hline OBDZ & outer- $\boldsymbol{\beta}$-depletion zone \\
\hline $\mathrm{RE}$ & reactive element \\
\hline SE & secondary electron \\
\hline SEM & scanning electron microscopy \\
\hline $\mathrm{TBC}$ & thermal barrier coating \\
\hline TCF & thermal cycling fatigue \\
\hline TCP & topological close packed \\
\hline $\mathrm{TMF}$ & thermal mechanical fatigue \\
\hline TGO & thermally grown oxide \\
\hline WDS & wavelength dispersive spectroscopy \\
\hline XRD & $\mathbf{x}$-ray diffraction \\
\hline
\end{tabular}




\section{Contents}

Abstract

Acknowledgement $\quad$ v

List of papers $\quad$ vii

Abbreviations $\quad$ ix

Contents $\quad$ xi

Part I Background and Theory 1

1 Introduction 3

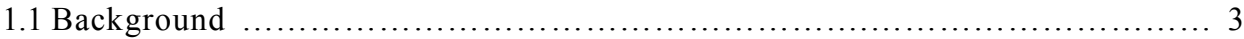

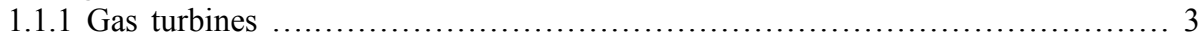

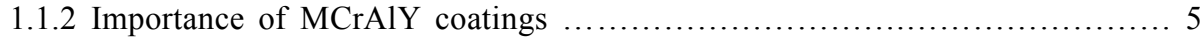

1.2 The project - why new MCrAlX? ............................................... 5

2 Superalloy-Coating System 7

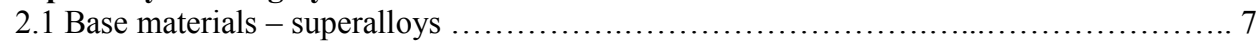

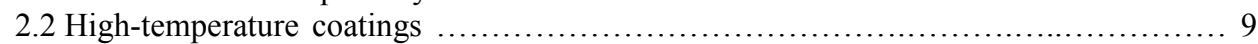

3 Oxidation and Hot Corrosion of Coatings 13

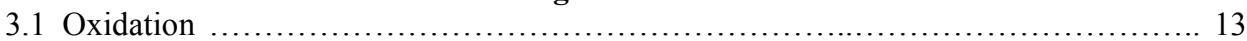

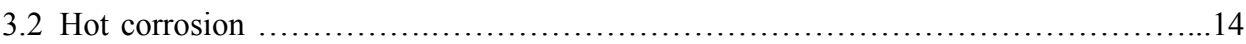

4 Interaction between Coating and Substrate 17

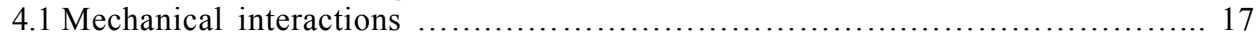

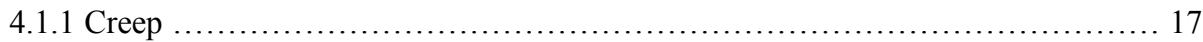

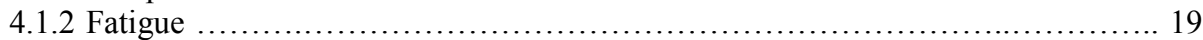

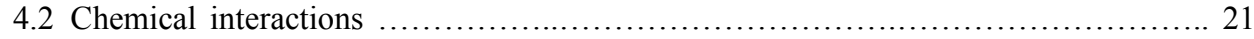

5 Modelling $\quad 23$

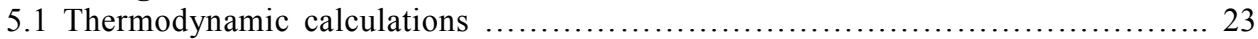




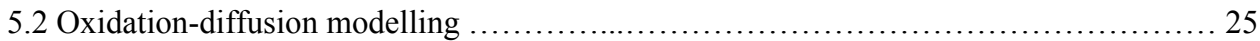

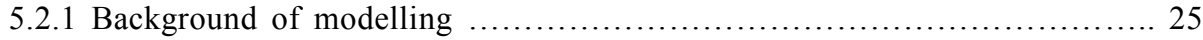

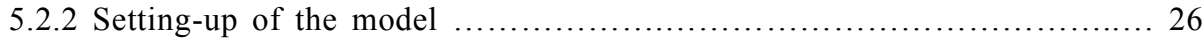

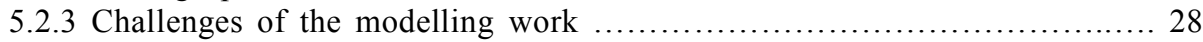

6 Methods 29

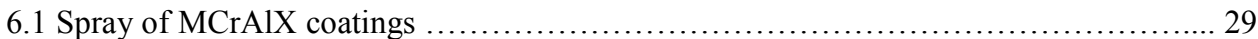

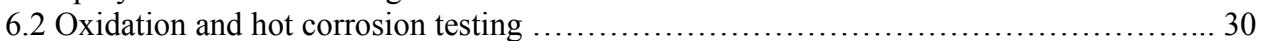

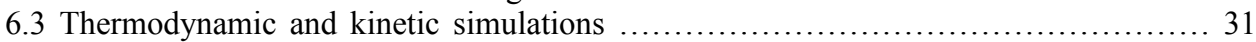

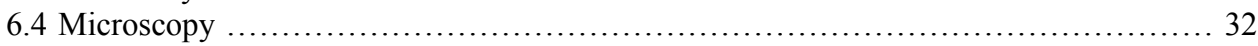

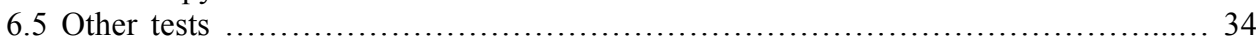

7 Summary of Appended Papers 35

$\begin{array}{ll}\text { Bibliography } & 41\end{array}$

$\begin{array}{ll}\text { Part II Appended Papers } & 47\end{array}$

Paper I: Modeling of microstructural evolution and lifetime prediction of MCrAlY coatings on nickel based superalloys during high temperature oxidation 49

Paper II: MCrAlY Coating design based on oxidation-diffusion modelling. Part I: Microstructural evolution

Paper III: MCrAlY coating design based on oxidation-diffusion modelling. Part II: Lifing aspects

Paper IV: Simulation of oxidation-nitridation-induced microstructural degradation in a cracked Ni-based superalloy at high temperature

Paper V: Some aspects of elemental behaviour in HVOF MCrAlY coatings in high-temperature oxidation

Paper VI: Hot corrosion behavior of MCrAlY coatings containing Ru and Ir

Paper VII: Hot corrosion of MCrAlY coatings in sulphate and $\mathrm{SO}_{2}$ environment at $900{ }^{\circ} \mathrm{C}$ : is $\mathrm{SO}_{2}$ necessarily bad? 


\section{Part I}

\section{Background and Theory}





\section{1 \\ Introduction}

\subsection{Background}

With a requirement to improve fuel efficiency and reduce $\mathrm{CO}_{2}$ emissions in gas turbines for industry applications or aircraft engines, development of gas turbines strongly demands not only a design of a good gas turbine system (heat transfer, cooling system, etc.), but also a development of materials which can be durably used at elevated temperatures (materials like superalloys, hightemperature coatings, etc.) $[1,2]$.

\subsubsection{Gas turbines}

Fig. 1 shows two Siemens land-based gas turbines - SGT-750 and SGT-800, which are used for power generation or mechanical drive [3]. During the operation of the gas turbines, air is taken through the INTAKE section, and is compressed by compressing blades in the COMPRESSION part. The compressed air goes further into the COMBUSTION chambers and is mixed with fuels, which are then ignited producing the high-temperature and high-pressure gases. The hot gases, with really high velocity, impact the blades and vanes in the TURBINE section to drive the rotation of the shaft to generate power. After passing the TURBINE section, the gases leave the gas turbine through the EXHAUST part, with a decreased temperature and pressure. Gas turbines, like ones presented in Fig. 1, can have a high energy efficiency, for instance about $40 \%$ by the SGT 750 [3].

Various materials are used in gas turbines in different sections referencing their mechanical properties and the temperature limitation. For the land-based gas turbines in Fig. 1, the INTAKE and COMPRESSION parts generally stay at lower temperatures $\left(<600^{\circ} \mathrm{C}\right)$, therefore, Fe-based alloys are widely chosen for the manufacture of the components in these sections. In an aero engine, high-strength and light $\mathrm{Al} / \mathrm{Ti}$ alloys are usually used in the cold parts of the engine [4]. The compressed air becomes very hot in the end of the COMPRESSION section, and the temperature will further and dramatically rise up in the COMBUSTION and TURBINE sections. In those sections, $\mathrm{Ni}$ - or Co-based superalloys are used as the base material for the blades and vanes to sustain high stresses even up to about $800{ }^{\circ} \mathrm{C}[1,4]$. Protective coatings are also required to protect the superalloy-made components from high-temperature oxidation and hot corrosion. The coatings are usually aluminum and/or chromium rich to form a thin, dense, continuous and protective alumina or chromia scale at the coating surface to shield the harsh atmosphere. In some parts of the gas turbine where the alloys can not sustain the high gas temperature directly, 
ceramic coatings, associated by an internal cooling system in the components, are also coated onto the components to decrease the temperature of the inner metallic materials [5].
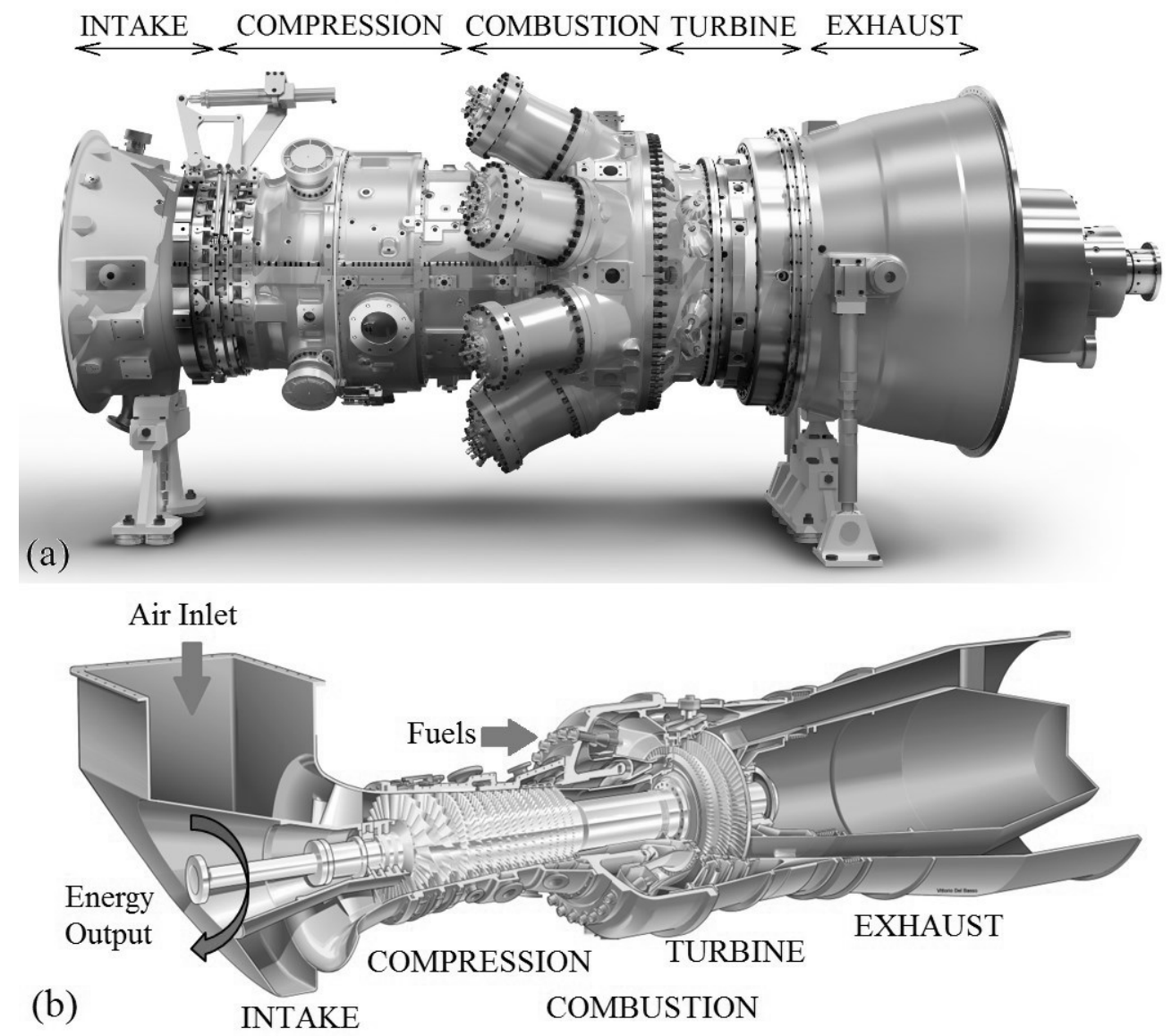

Figure 1. Two Siemens gas turbines (produced in Finspång, Sweden): (a) SGT-750 (38 MW), (b) SGT800 (47 MW).

\subsubsection{Importance of MCrAlY coatings}

MCrAlY coatings ( $\mathrm{M}$ for $\mathrm{Ni}$ and/or $\mathrm{Co}$ ) are largely applied for high-temperature oxidation and hot corrosion resistance to protect the base materials in some hot components in gas turbines. MCrAlY coatings can be used as overlays (e.g. on the blades in the end part of the COMBUSTION section, and, on the blades and vanes in the low-temperature part of the TURBINE section), or as bond coats in thermal barrier coating (TBC) systems (e.g. on the COMBUSTION chamber, and, on the components in high-temperature part of the TURBINE section). MCrAlY coatings are widely used in gas turbines because of many reasons [4,6-8]: 
- MCrAlY coatings can protect substrate materials from high-temperature oxidation and hot corrosion by forming a protective oxide scale on the coatings;

- The coating composition can be tailored for various application needs;

- Coating thickness can be easily varied to various demands, such lifetime, aerodynamics, and etc.;

- Many deposition or spray techniques are available to manufacture MCrAlY coatings;

- MCrAlY coatings can have a good combination of strength and ductility at high temperature;

- If being as a bond coat, the use of MCrAlY coating in a TBC system can enhance the bonding strength between the ceramic layer and the metallic materials significantly.

\subsection{The project - why new MCrAlX?}

Traditionally, "MCrAlY" is usually used to name the alloys or coatings containing $\mathrm{Cr}, \mathrm{Al}$ and $\mathrm{Y}$ with $\mathrm{Ni}$ and/or $\mathrm{Co}$ as the base elements. In such coatings, Y performs as a reactive element at high temperature and plays an important role in the formation of alumina scale and the scale adherence on the coatings. In this project, "MCrAlX" is adapted to strengthen the effects of other alloying elements besides $Y$, namely the " $\mathrm{X}$ " elements, like silicon, tantalum, ruthenium, iridium, and etc., in the spirit of new MCrAlX coating design. The phrase of "MCrAlX" was also used by few other researchers in literature $[9,10]$. By optimizing the concentrations of $\mathrm{X}$ elements, the properties of the new MCrAlX coatings, including oxidation resistance, hot corrosion resistance and coating strength and ductility, are aimed to be improved. To make this thesis easy to read, "MCrAlY" is still adapted in the following chapters.

In this four-year PhD project (2010-2014), both experimental testing and modelling work were carried out to support the new MCrAlX-coating design. Experiments mainly contained oxidation and hot corrosion testing of the new MCrAlX coatings, while modelling work was done by using ThermoCalc and DICTRA software for both equilibrium calculations and diffusion simulations. Based on the outcomes produced in this project, more research will be continued in the future:

- Mechanical property testing, e.g. creep and fatigue behavior (e.g. thermal mechanical fatigue) of the MCrAlX coatings in superalloy-coating systems;

- New coating composition development based on the model which has been built in the project;

- Investigation of the oxidation/corrosion behavior of the new MCrAlX coatings in a TBC system. 


\section{Superalloy-Coating System}

\subsection{Base materials - superalloys}

Since 1940s, the manufacturing process of superalloys has been highly developed mainly aiming to improve the creep capacity: wroughting $\rightarrow$ conventionally casting $\rightarrow$ directionally solidifying $\rightarrow$ single crystal $[4,11]$. Voids and cracks can form at grain boundaries in polycrystalline alloys which could make the alloy fail earlier during a creep process [12]. By removing the grain boundaries from the alloys, the creep resistance can be dramatically improved: for example for the same creep lifetime, the creep temperature can be increased by about $100{ }^{\circ} \mathrm{C}$ for single-crystal superalloys in comparison with casted ones [4]. However, in the real industrial applications, polycrystalline superalloys still hold the most markets of superalloys, because of the lower cost to make a poly crystal than a single crystal.

In the latest generations, the superalloys are generally Ni-based FCC alloys since Ni has a high ability for elemental solution in it and owns a low thermal activity rate which is beneficial for creep resistance. The FCC matrix in Ni-based superalloys can be strengthened by dissolving other alloying elements (solid-solution strengthening), forming strengthening precipitates like $\gamma^{\prime}$, $\gamma^{\prime \prime}$ and/or carbides (precipitation strengthening), or dispersing some oxide-particles like $\mathrm{Y}_{2} \mathrm{O}_{3}$ (oxide-dispersion strengthening) [1]. Co superalloys are usually strengthened by solid solution in tradition $[4,11]$, but recently $\mathrm{Co}-\mathrm{W}-\mathrm{Al}$ systems are also developed with the $\gamma^{\prime}$-precipitation strengthening [13].

Table 1. The composition (wt.\%) of Inconel 792 and its heat-treatment processes.

\begin{tabular}{cccccccccccc}
\hline $\begin{array}{c}\text { Composition } \\
\text { (wt.\%) }\end{array}$ & $\mathrm{Ni}$ & $\mathrm{Cr}$ & $\mathrm{Co}$ & $\mathrm{W}$ & $\mathrm{Ta}$ & $\mathrm{Ti}$ & $\mathrm{Al}$ & $\mathrm{Mo}$ & $\mathrm{C}$ & $\mathrm{Zr}$ & $\mathrm{B}$ \\
\cline { 2 - 10 } & $\mathrm{Bal}$. & 12.5 & 9.0 & 4.2 & 4.2 & 4.0 & 3.4 & 1.9 & 0.08 & 0.018 & 0.015 \\
\hline $\begin{array}{c}\text { Heat-treatment } \\
\text { processes }\end{array}$ & \multicolumn{1}{c}{ Solution annealing: $(1120 \pm 10){ }^{\circ} \mathrm{C}$ for 2 hours in vacuum; } \\
Ageing: $(845 \pm 10){ }^{\circ} \mathrm{C}$ for 24 hours. \\
\hline
\end{tabular}

Generally a number of alloying elements are added in a superalloy to modify the microstructure and improve the mechanical properties. The composition of Inconel 792, a Ni-based polycrystalline superalloy which is always used as the substrate in this $\mathrm{PhD}$ project, is shown in Table 1. Due to its complex chemical composition, a considerable number of phases can form in the alloy. Fig. 2a shows the typical microstructure of this superalloy (casted) after the solution annealing and ageing heat treatments given in Table 1. In the grains, $\gamma^{\prime}$ (ordered FCC) precipitates can be found in a $\gamma$ (disordered FCC) matrix. Depending on the $\gamma-\gamma^{\prime}$ lattice misfit the 
morphology of $\gamma^{\prime}$ can be cubic, spherical or cuboidal [4]. Carbides also form in the superalloy, in a form of $\mathrm{MC}$ or $\mathrm{M}_{23} \mathrm{C}_{7}$. If being at grain boundaries, the carbides can improve the creep resistance by hindering grain-boundary sliding [14].
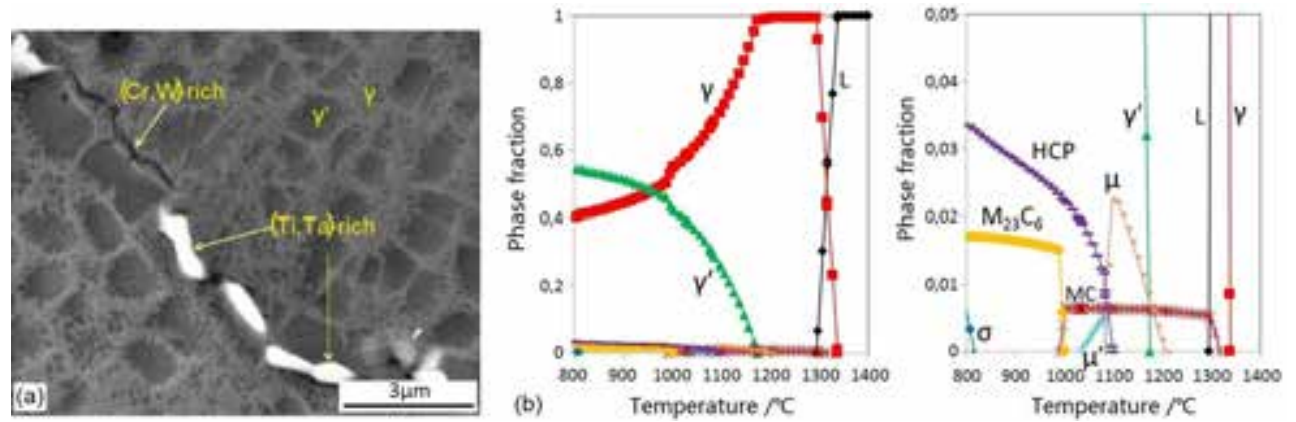

Figure 2. Microstructure in Inconel 792 after the solution annealing and ageing heat treatments: (a) showing $\gamma^{\prime}$ precipitates in $\gamma$ matrix and grain-boundary carbides, and (b) showing the equilibrium microstructure in Inconel 792 calculated by Thermo-Calc software with the Ni-based thermodynamic database TCNI5.

Table 2. Some phases that may form in superalloys [1,4,13,15-17].

\begin{tabular}{|c|c|c|c|}
\hline Phase & Formula & $\begin{array}{r}\text { Crystal } \\
\text { Structrure }\end{array}$ & $\begin{array}{r}\text { Thermaldynamic Stable } \\
\text { Temp. }\end{array}$ \\
\hline$\beta$ & $\mathrm{NiAl}$ & BCC (ordered) & \\
\hline$\gamma$ & - & FCC (disorderd) & up to melting point \\
\hline \multirow[t]{2}{*}{$\gamma^{\prime}$} & $\mathrm{Ni}_{3}(\mathrm{Al}, \mathrm{Ti}, \mathrm{Ta})$ in $\mathrm{Ni}$ based superalloy & FCC (ordered) & up to $1200^{\circ} \mathrm{C}$ \\
\hline & $\mathrm{Co}_{3}(\mathrm{Al}, \mathrm{W})$ in Co based superalloy & FCC (ordered) & up to $1150^{\circ} \mathrm{C}$ \\
\hline$\gamma^{\prime \prime}$ & $\mathrm{Ni}_{3} \mathrm{Nb}$ & BCT (ordered) & up to $885^{\circ} \mathrm{C}$ \\
\hline$\delta$ & $\mathrm{Ni}_{3} \mathrm{Nb}$ & orthorhombic & $650-980^{\circ} \mathrm{C}$ \\
\hline$\eta$ & $\mathrm{Ni}_{3} \mathrm{Ti}$ & HCP & - \\
\hline$\sigma$ & $\mathrm{Cr}_{2} \mathrm{Ru}, \mathrm{Cr}_{61} \mathrm{Co}_{39}, \mathrm{Re}_{67} \mathrm{Mo}_{33}$ & tetragonal & $540-980{ }^{\circ} \mathrm{C}$ \\
\hline$\mu$ & $\mathrm{Co}_{2} \mathrm{~W}_{6},(\mathrm{Fe}, \mathrm{Co})_{7}(\mathrm{Mo}, \mathrm{W})_{6}$ & rhombohedral & - \\
\hline $\mathrm{P}$ & $\begin{array}{r}\mathrm{Cr}_{18} \mathrm{Mo}_{43} \mathrm{Ni}_{40}, 43 \mathrm{Re}-20 \mathrm{~W}-23 \mathrm{Ni}-5.3 \mathrm{Cr}-7.2 \mathrm{Co}- \\
\text { others (wt.\%) }\end{array}$ & orthorombic & - \\
\hline $\mathrm{R}$ & $\mathrm{Fe}_{52} \mathrm{Mn}_{16} \mathrm{Mo}_{32}$ & rhombohedral & - \\
\hline laves & $\mathrm{Co}_{2}(\mathrm{Ta}, \mathrm{Ti}), \mathrm{Fe}_{2} \mathrm{Ti}$ & hexagonal & - \\
\hline \multirow[t]{5}{*}{ carbide } & $\mathrm{MC}(\mathrm{M}=\mathrm{Ti}, \mathrm{Ta}, \mathrm{Nb}, \mathrm{W}, \mathrm{Mo}, \mathrm{Hf}, \mathrm{Cb}, \mathrm{Zr})$ & cubic & up to melting point \\
\hline & $\mathrm{M}_{23} \mathrm{C}_{7}(\mathrm{M}=\mathrm{Cr}, \mathrm{Fe}, \mathrm{Mo}, \mathrm{W})$ & FCC & $760-980^{\circ} \mathrm{C}$ \\
\hline & $\mathrm{M}_{7} \mathrm{C}_{3}(\mathrm{M}=\mathrm{Cr})$ & hexagonal & above $1000^{\circ} \mathrm{C}$ \\
\hline & $\mathrm{M}_{6} \mathrm{C}(\mathrm{M}=\mathrm{Mo}, \mathrm{W}, \mathrm{Cr}, \mathrm{Fe}, \mathrm{Co}, \mathrm{Ta})$ & FCC & $815-980^{\circ} \mathrm{C}$ \\
\hline & $\mathrm{M}_{3} \mathrm{C}_{2}(\mathrm{M}=\mathrm{Cr})$ & rhombic & - \\
\hline boride & $\mathrm{M}_{3} \mathrm{~B}_{2}(\mathrm{M}=\mathrm{Cr}, \mathrm{Mo}, \mathrm{Nb}, \mathrm{Ti}, \mathrm{Ni}, \mathrm{Fe}, \mathrm{V})$ & tetragonal & - \\
\hline
\end{tabular}

Fig. $2 \mathrm{~b}$ presents the calculated equilibrium microstructure in Inconel 792 between $800{ }^{\circ} \mathrm{C}$ and $1200{ }^{\circ} \mathrm{C}$ (The composition in the calculation used is Ni-12.5Cr-9Co-4.175W-4.175Ta-3.975Ti$3.375 \mathrm{Al}-1.9 \mathrm{Mo}-0.08 \mathrm{C}$ by wt.\%). According to the calculation, the first solid phase $-\gamma$ is expected to form in the melt at around $1340^{\circ} \mathrm{C}$ during cooling. (Ti,Ta)-rich MC carbides can also form in the $\gamma$ matrix during the solidification $[1,4,15]$. When decreasing temperature, the 
following transformation among minor phases may occur: $\mathrm{MC} \rightarrow \mathrm{M}_{7} \mathrm{C}_{3} \rightarrow \mathrm{M}_{23} \mathrm{C}_{6} / \mathrm{M}_{6} \mathrm{C} \rightarrow \sigma$, suggested by [1]. Topologically-close packed (TCP) phases such as (Cr,W)-rich $\mu$-phase may also form at high temperatures. Decreasing temperature lowers the solubility of alloying elements in the $\gamma$ phase, promoting the formation of $\gamma^{\prime}$ and other phases. In the ageing treatment at $845^{\circ} \mathrm{C}$ some ( $\mathrm{Cr}, \mathrm{Mo})$-rich $\mathrm{M}_{23} \mathrm{C}_{6}$ carbides could form at grain boundaries [18] and $(\mathrm{Co}, \mathrm{W})-\mathrm{HCP}$ phase is also predicted by the calculation but not detected in SEM observation. The diffusivity of the alloying elements becomes slower at lower temperatures, leading to sluggish microstructure changes, and then the comparison between the calculation results and the real microstructure in the alloy becomes tricky. For example, the (Ti,Ta)-rich MC, which is thermodynamically unstable at $845^{\circ} \mathrm{C}$ according to the calculation (Fig. 2b), is actually well kept after the ageing treatment at $845^{\circ} \mathrm{C}$ (Fig. 2a). The mismatch between the calculated microstructure and the real one can be also due to the inevitable imperfection of the database used in the calculation.

Phases in Ni-based and Co-based superalloys which have been reported in literatures are summarized in Table $2[1,4,13,15-17]$. Typically, the TCP phases, namely $\sigma, \mu, \mathrm{P}$ and $\mathrm{R}$, have complex chemical formulas usually containing many atoms in one unit cell. The volume fraction of those TCP phases should be controlled to a small extent in alloy design with the consideration of the material ductility.

\subsection{High-temperature coatings}

High-temperature coatings used in gas turbines can be generally classified into metallic coatings and thermal barrier coating (TBC). Metallic coatings include diffusion coating and MCrAlY overlay coating; the metallic coatings can be also utilized as bond coats in TBC systems. Typical morphologies of the cross sections of those coatings are shown in Fig. 3. A good coating design should consider many factors as listed in Table 3.

Table 3. Desirable coating requirements for coating-superalloy systems in gas turbines (mainly based on the summarizations by $[8,19])$.

\begin{tabular}{ll}
\hline Coating Property & Requirements \\
\hline Oxidation/Corrosion & Rapid formation of an initial oxide scale; \\
Resistance & Protective scale: uniform, adherent, stable and ductile; \\
& Slow and uniform scale growth; \\
& Ability to quickly form a new protective scale after oxide scale spallation. \\
Material Stability & Low coating-forming stress; \\
& Good ability to keep the beneficial elements and microstructure in the \\
& coating for oxidation resistance; \\
& Limited interdiffusion across coating-substrate interface; \\
& Limited the formation of brittle phases across coating-substrate interface; \\
& Clean coating-substrate interface. \\
& Ability to withstand all stress (creep, fatigue, and impact loading); \\
& Appropriate coating ductility; \\
& Mechanical match between coating and substrate; \\
Mechanical Property & Minimum effects on substrate properties. \\
&
\end{tabular}




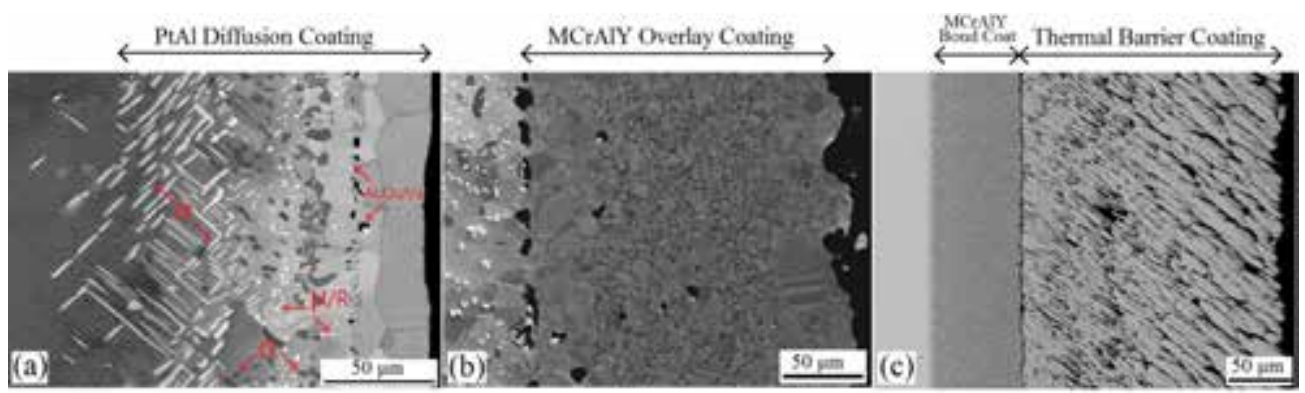

Figure 3. High-temperature coatings (cross sections): (a) PtAl diffusion coating deposited by CVD, (b) MCrAlY overlay coating sprayed by HVOF, and (c) thermal barrier coating deposited by EB-PVD (MCrAlY as a bond coat deposited by EB-PVD).

Diffusion coatings are produced by a process with the enrichment of one or several elements at the surface of a substrate material [6]. For instance, aluminide diffusion coating (NiAl) is produced by the surface enrichment of Al-rich species followed by an inward diffusion of $\mathrm{Al}$ or outward diffusion of $\mathrm{Ni}$; diffusion direction is dependent upon the $\mathrm{Al}$ activity during the aluminizing process. If the $\mathrm{Al}$ content at the substrate surface is low and the aluminizing temperature is high $\left(>1000{ }^{\circ} \mathrm{C}\right)$, the outward diffusion of $\mathrm{Ni}$ prevails, creating an outward diffusion coating. If the $\mathrm{Al}$ activity is high and a low temperature $\left(<800{ }^{\circ} \mathrm{C}\right)$ is applied, the inward diffusion of $\mathrm{Al}$ is predominant, resulting in an inward diffusion coating [6]. Since the substrate participates in the formation of the diffusion coatings, the microstructures in the diffusion coatings highly rely on the composition of the substrate material. Pt can be deposited on a superalloy by electroplating or physical-vapor deposition (PVD), followed by traditional aluminization to form the Pt-modified aluminide (PtAl) [20]. Diffusion coatings can be fabricated by pack process or chemical-vapor deposition (CVD) method [6]. The operation temperature of diffusion coatings are generally lower than $1000^{\circ} \mathrm{C}$ [8].

MCrAlY overlay coatings have less dependence on the substrate composition than the diffusion coatings. To make the MCrAlY overlay coatings, the precursors with the designed composition in a form of powders or wires can be sprayed onto the substrate materials. The concentration of $\mathrm{Cr}$ and $\mathrm{Al}$ is important for the oxidation and hot corrosion resistance of the coatings which, typically, have a composition of 15-22 wt.\% $\mathrm{Cr}$ and 8-12wt.\% $\mathrm{Al}[7,8]$. By optimizing the concentrations of some minor elements like $\mathrm{Y}, \mathrm{Si}, \mathrm{Hf}$ and $\mathrm{Ta}$, one can improve the performance of the coatings at high temperature. For example $\mathrm{Y}$ is added to promote the formation of the protective $\mathrm{Al}_{2} \mathrm{O}_{3}$ scale [21] and improve the adhesion of the scale [22]. The addition of Si and Hf may provide beneficial effect on hot corrosion resistance, while some heavier elements like Ta in the coating may affect the diffusion activities of alloying elements by reducing their diffusion rates [6]. MCrAlY coatings can be deposited or sprayed by a number of techniques: atmospheric plasma spraying (APS), low-pressure plasma spraying (LPPS), vacuum plasma spraying (VPS), electron-beam physical vapor deposition (EB-PVD), and high-velocity oxy-fuel spraying (HVOF) [23-26].

Thermal barrier coatings (TBCs) are used to decrease the temperature of the underlying bond coat and based alloy from the hot gases in combustion and turbine sections in gas turbines. By cooperating with the internal cooling systems in the metallic components, TBCs can provide a 200 to $300{ }^{\circ} \mathrm{C}$ temperature decrease at the component surface; the exact value of the temperature 
decrease is dependent on the thickness and thermal conductivity of the TBCs [6,11], and the design of the components. Yttria (partially) stabilized zirconia is the most common TBC material used in the industries now, due to its low thermal conductivity, relatively large thermal expansion, and advisable price $[6,27,28]$. To achieve higher thermal isolating effect, microstructures in the TBCs can be modified to reduce the thermal conductivity. To be more strain tolerance, columnar TBCs are preferred, which can be produced by EB-PVD [6,27,28], like the one shown in Fig. 3c. One critical failure mode of TBCs is the spallation of the top ceramic coat from the bond coat, for which the surface roughness of the bond coat and quality of the thermally-growing oxide scale become very important [27]. 


\section{3 \\ Oxidation and Hot Corrosion of Coatings}

\subsection{Oxidation}

In combustion and turbine sections in gas turbines, components face considerable attacks of hightemperature oxidation [23]. Coatings, used for the protection against the oxidation, are required to form a continuous, dense, easy for repair, and protective oxide scale at the coating surface to hinder the inward diffusion of oxygen and other species from the atmosphere therefore to slow down the material degradation due to the oxidation. Coating degradation in an oxidation process can be divided into three stages: transient stage (oxides fast forming), steady stage (one predominate oxide growing, spalling, and maintaining) and coating failure (protective scale unable to form or to be maintained), as schematically shown in Fig. 4a.
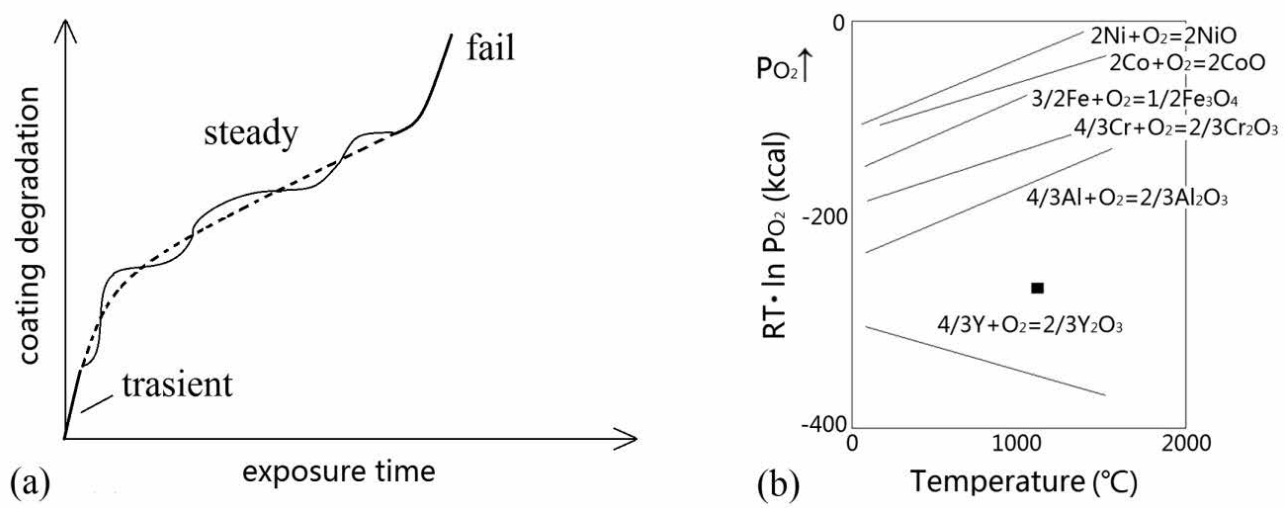

Figure 4. (a) schematic illustration of the three stages of the coating degradation due to oxidation (hand drawing based on [29]), (b) Ellingham diagram showing the free energy of the formation of the oxides as a function of temperature (data for the oxides of $\mathrm{Ni}, \mathrm{Co}, \mathrm{Fe}, \mathrm{Cr}$ and $\mathrm{Al}$ come from [6], data for the oxide of Y come from [30], the point, and [31], the line).

In the transient stage (Fig. 4a), almost all alloying elements can be oxidized at the coating surface, forming a variety of oxides which could be an unstable aluminum oxide $\left(\gamma-, \delta\right.$ - or $\theta-\mathrm{Al}_{2} \mathrm{O}_{3}[32-$ $34]), \mathrm{Cr}_{2} \mathrm{O}_{3}, \mathrm{CoO}, \mathrm{NiO}$ and/or spinels [7,34-36]. The variety of the transient oxides is mainly dependent upon the chemical composition and the microstructures of the coating. Other factors 
like temperature and partial oxygen pressure can also affect the formation of the oxides [7]. With prolonged oxidation time the transient aluminum oxides will be converted into stable $\alpha-\mathrm{Al}_{2} \mathrm{O}_{3}$ while other oxides such as $\mathrm{Cr}_{2} \mathrm{O}_{3}$, NiO, etc. can remain during the steady oxidation stage [36]. The transient stage is usually very short, for instance, less than 1 hour for $\mathrm{Ni}-\mathrm{Cr}$-Al alloys above $1000{ }^{\circ} \mathrm{C}[35,37]$.

As shown in Fig. 4b, comparing with the oxides of other main elements ( $\mathrm{Ni}, \mathrm{Co}, \mathrm{Cr}$.), the oxide of $\mathrm{Al}$, alumina $\left(\alpha-\mathrm{Al}_{2} \mathrm{O}_{3}\right)$ has a lower formation energy, and is always the chosen oxide to form a continuous and dense scale against high-temperature oxidation in MCrAlY coatings. The formation energy of alumina $\left(\Delta G^{0}\right)$ in an alloy can be calculated by following equation:

$$
\Delta G^{0}=R T \ln \left[a_{A l}^{4 / 3} \cdot P_{O_{2}}\right]
$$

where $R$ is the gas constant, $T$ is temperature in Kelvin, $a_{A l}$ is the activity of aluminum, and $P_{O_{2}}$ is the partial pressure of oxygen. The activity of aluminum is alloying composition dependent. Oxides of some reactive elements, like yttia $\left(\mathrm{Y}_{2} \mathrm{O}_{3}\right)$, have even lower formation energy, which can affect the oxidation behavior of coatings in the transient stage. For instance, $\mathrm{Y}$ can facilitate the formation of the alumina scale [38].

In the steady stage, alumina grows as a continuous, dense, and protective scale, with the support of $\mathrm{Al}$ from the underlying coating matrix. In this stage, the alumina scale may spall off, due to its growth stress (increasing with the scale thickness [39]), or the thermal stress (caused due to temperature cycling $[40,41]$ ). The addition of small amount of reactive elements like Y and Hf can improve the adhesion of the alumina scale [42-44]. After the spallation of the scale, a fresh surface of the underlying coating will be exposed to atmosphere and will be oxidized to form new oxides. If the coating can quickly heal the alumina scale, the coating's life can be prolonged.

When the $\mathrm{Al}$ content in the coating is lower than a critical level, the coating will be incapable to support the growth and the maintenance of the alumina scale, and then other oxides like $\mathrm{NiO}$, $\mathrm{CoO}$, and/or spinels will aggressively form which usually can not form a dense and protective scale like alumina for oxidation resistance [7,45-49]. In this case, the coating will deteriorate rapidly to fail.

\subsection{Hot corrosion}

Hot corrosion on metallic coatings can be classified into Type I and Type II [6]. The temperature range and the damage on the coatings are illustrated in Fig. 5. Type I hot corrosion occurs above a certain temperature $\left(800-950{ }^{\circ} \mathrm{C}\right.$ [8]) when the detrimental salts (e.g. sulphates like $\mathrm{Na}_{2} \mathrm{SO}_{4}$, $\mathrm{K}_{2} \mathrm{SO}_{4}$ ) are melted to dissolve the oxide scale. This process usually produces a porous oxide layer and the underlying alloy/coating with a sulfidation attack [6]. At lower temperature $\left(600-800{ }^{\circ} \mathrm{C}\right.$ [8]), pitting attack with minimal sulfidation is commonly found, leading to the type II hot corrosion [6]. The damage by the hot corrosions depends on many factors such as coating composition, thermomechanical condition, contaminant composition, flux rate, temperature, corrosion time, gas composition and velocity, and erosion [50]. For instance, coexistence of 
$\mathrm{NaCl} / \mathrm{V}_{2} \mathrm{O}_{5}$ with sulfates can form the eutectics of low-melting temperature, which expands the temperature range of the hot-corrosion attack [8,50,51]. Some corrosive salts, oxides and eutectics with their melting points are shown in Table 4; note that the eutectics of some salts have a lower melting point than the single salts.

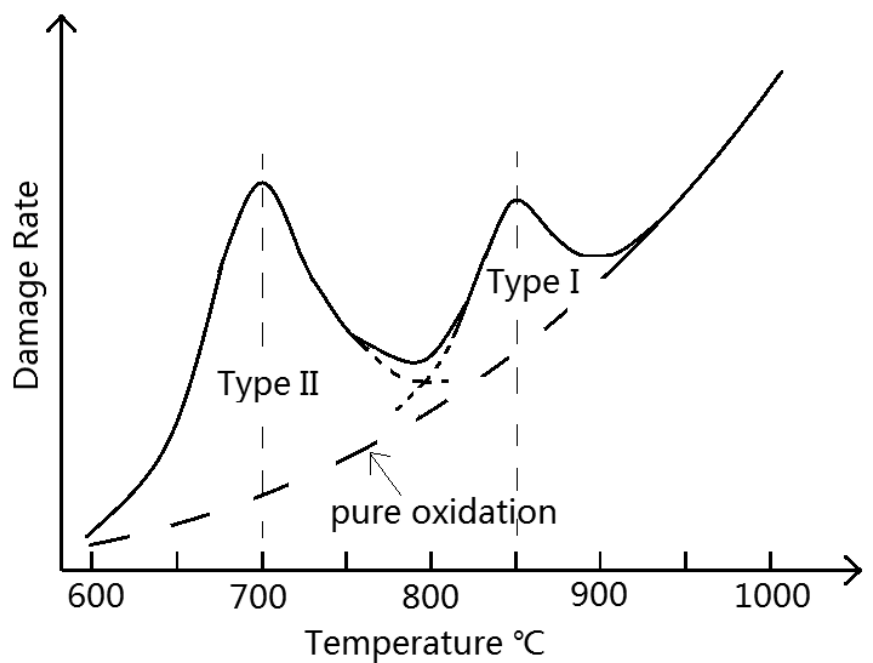

Figure 5. Schematic illustration of damage due to type I and II hot corrosion superimposed on contribution to pure oxidation. The corrosion regime is based on $[6,8]$.

Table 4. Melting point of some salts, oxides and eutectics $[6,50,52]$

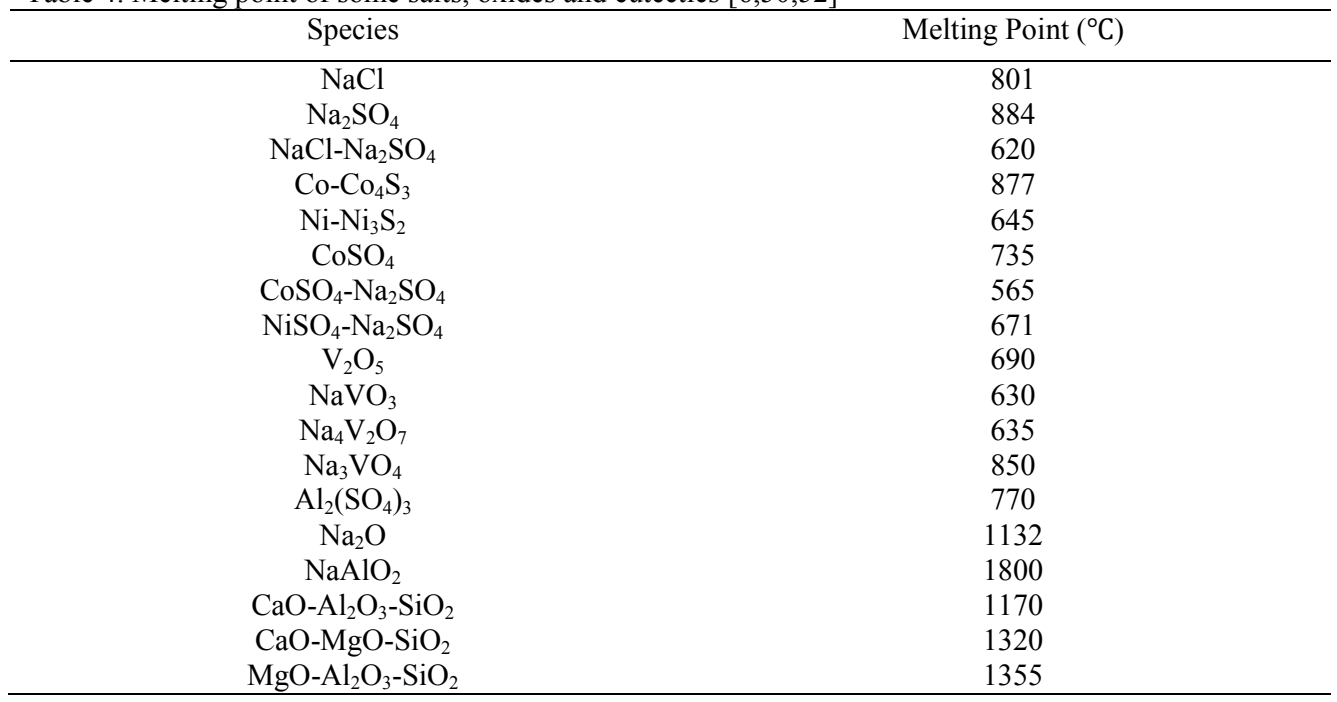


The true mechanism of hot corrosion is not completely understood yet. But a commonly accepted mechanism is the "fluxing" of the protective oxides in the molten salt due to the gradients of the oxides' solubility through the salt thickness [6,53]. Such mechanism is particularly accepted for the type I hot corrosion.

The most common salt causing the hot corrosion in gas turbines is sodium sulphate - $\mathrm{Na}_{2} \mathrm{SO}_{4}$ [50,54-56]. Dependent on the basicity (or acidity) of the molten salts, an oxide scale like alumina can be dissolved, basically, in two ways [53,57-59], as shown in the underlying equations. The basicity (or acidity) of the molten salts is controlled by the thermodynamic activity of $\mathrm{Na}_{2} \mathrm{O}$ or $\mathrm{SO}_{3}[53,59]$.

$$
\begin{aligned}
& \text { (Basic fluxing) } 2 \mathrm{Na}_{2} \mathrm{O}+2 \mathrm{Al}_{2} \mathrm{O}_{3}=4 \mathrm{NaAlO}_{2} \\
& \text { (Acidic fluxing) } \mathrm{Al}_{2} \mathrm{O}_{3}+3 \mathrm{SO}_{3}=\mathrm{Al}_{2}\left(\mathrm{SO}_{4}\right)_{3}
\end{aligned}
$$

Fig. 6 shows an example of the cross-sectional microstructure of the oxide layer after a basicfluxing process in a sulphate environment at $900{ }^{\circ} \mathrm{C}$. The layer is not pure alumina scale any more but a mixture of different oxides; in the case in Fig. 6, the mixed oxides are $\mathrm{Al}$ oxides, $\mathrm{Cr}$ oxides, spinels and some S-rich species. Chromia $\left(\mathrm{Cr}_{2} \mathrm{O}_{3}\right)$ is believed to be a oxide to be resistant against the fluxing attack, because chromia at the salt-gas interface has a higher solubility in the molten salt than at the salt-oxide interface, which can hinder the dissolution of the oxide into the molten salt $[6,53]$. Alumina and many other oxides (e.g. NiO) have the opposite solubility at the salt-gas and salt-oxide interfaces, therefore are less resistant against the hot corrosion $[6,53]$. Many researches have studied the hot corrosion behavior of MCrAlY coatings in molten-sulphate environments [60-65]. The corrosion behavior of those coatings is dependent on, for example, the salt chemistry [60] and the $\mathrm{SO}_{2}$ partial pressure $[66,67]$.

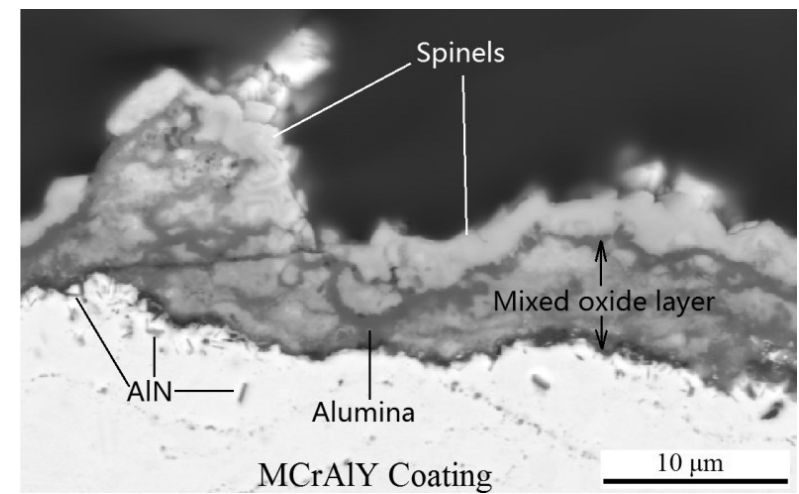

Figure 6. The morphology of the oxide layer on a MCrAlY coating after a type-I hot corrosion process at $900{ }^{\circ} \mathrm{C}$. 


\section{Interaction between Coating and Substrate}

\subsection{Mechanical interactions}

The mechanical interactions means the influence of the coating on the creep or fatigue behavior of the substrate material (superalloy). In this chapter, only the influence of metallic coatings is discussed.

\subsubsection{Creep}

Creep is a phenomenon that a solid material deforms slowly and permanently under a stress [1]. Creep of metals or alloys usually occurs when increasing temperature. In a coating-substrate system, the effect of the coating on the rupture of the substrate material becomes more pronounced when the substrate is thin [68].
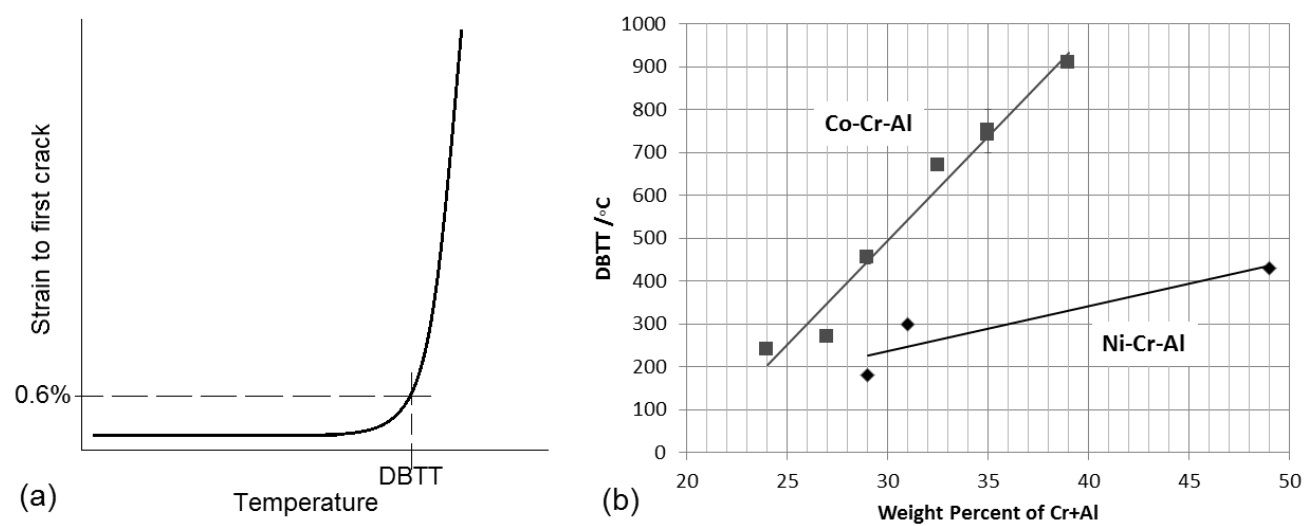

Figure 7. Ductile-brittle transition temperatures: (a) measurement of DBTT of material [69] and (b) DBTT values of $\mathrm{MCrAl}$ and $\mathrm{CoCrAl}$ alloy systems $[6,19]$.

Metals or alloys can become superior ductile when the temperature is above a critical value which is called ductile-to-brittle transition temperature (DBTT). The measurement of the DBTT is as shown in Fig. 7a proposed by Lowrie [69] who suggested DBTT is the temperature above which a minimal plastic strain of $0.6 \%$ should be obtained in a tensile test. There are also other 
definitions of DBTT [70]. DBTT for some NiCrAl and CoCrAl alloys [6,19] are shown in Fig. 7b, in which different DBTT definitions may be adapted for those alloys. DBTT of some other alloys are given in Table 5 .

Table 5. DBTT for some $\mathrm{X}_{\mathrm{m}} \mathrm{Al}_{\mathrm{n}}$ alloys and alumindes $[6,19,70]$.

\begin{tabular}{ll}
\hline Material & Estimated DBTT $\left({ }^{\circ} \mathrm{C}\right)$ \\
\hline $\mathrm{Ni}-35 \mathrm{Al}$ & $\sim 740$ \\
$\mathrm{Co}-35 \mathrm{Al}$ & $\sim 970$ \\
$\mathrm{PtAl}_{2}$ & $870-1070$ \\
$\mathrm{Ni}_{3} \mathrm{Al}$ & $730-900$ \\
$\mathrm{NiAl}$ & $868-1060$ \\
$\mathrm{CoAl}$ & $878-1070$ \\
$\mathrm{Ni}_{2} \mathrm{Al}$ & $570-710$ \\
$\mathrm{Plan}$ aluminide & 693 \\
Pt-aluminide & 795 \\
\hline
\end{tabular}

Fig. 8a presents the typical creep deformation stages: primary stage, steady stage and fracture. One theory to explain the different behavior of materials in those three stages is the creep hardening-softening by dislocation. Creep hardening is caused by dislocation multiplication while creep softening by dislocation recovery [4]. As can be seen in Fig. 8a, the strain rate decreases with time in the primary stage (due to creep hardening), then remains constant in the long steady stage (balance between creep hardening and softening) and finally increases in the final stage to failure (voids/cracks forming and growing). Dependent on the temperature and stress in the creep process, the shape of creep curve changes [1].

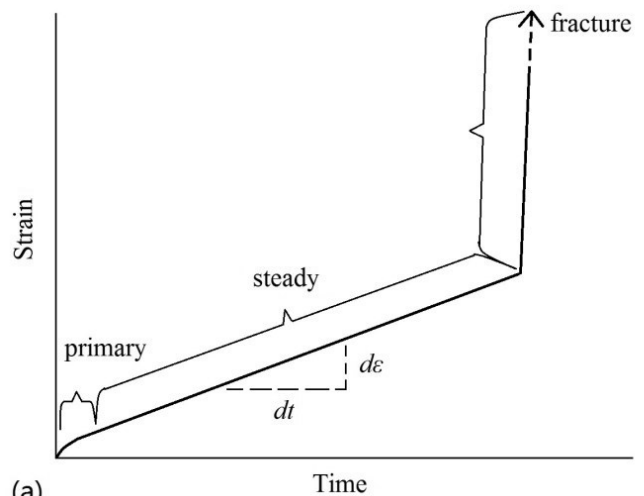

(a)

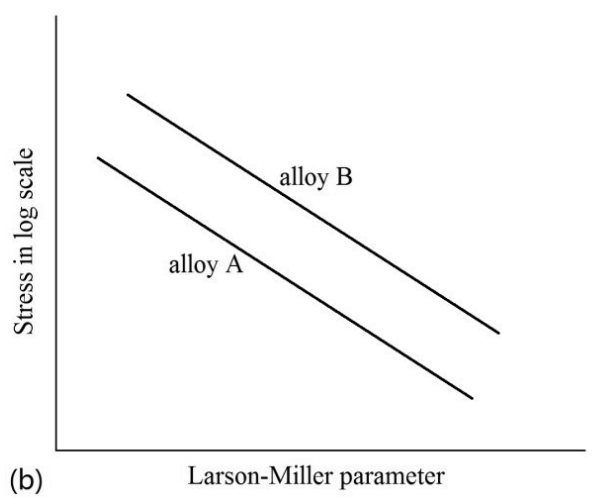

Figure 8. Creep deformation: (a) schematically illustration of a creep deformation process containing three stages, (b) Larson-Miller parameter to describe the alloy performance in creep (alloy B is more creep resistant than alloy A). The graphs are drawn based on [4].

The creep rate $\dot{\varepsilon}$ in the steady stage can be obtained from the strain-time curve in Fig. 8a:

$$
\dot{\varepsilon}=\frac{d \varepsilon}{d t}
$$


where $d \varepsilon$ is the strain increment during the time period $d t$. The creep rate $\dot{\varepsilon}$ is dependent upon the creep stress and temperature, and can be described by the following equation $[1,4]$ :

$$
\dot{\varepsilon}=C \sigma^{n} \exp \left(-\frac{Q}{R T}\right.
$$

where $\sigma$ is the creep stress, $n$ the stress exponent, $Q$ the activation energy, $R$ the gas constant, and $T$ the temperature. The time to rupture $\left(t_{r}\right)$ can be related to the creep rate through the MonkmanGrant relationship [1,4]:

$$
t_{r} \times \dot{\varepsilon}=\text { constant }
$$

By combining the above two equations, a so-called Larson-Miller parameter can be calculated $[1,4]$ :

$$
L M P=T\left(E+\log _{10} t_{r}\right)
$$

where $E$ is a constant which is usually set as 20. A higher Larson-Miller parameter means a longer creep life or a higher temperature can be applied. In Fig. 8b, alloy B has a higher creep resistance than alloy A.

In a coating-superalloy system, the coating almost carries no stresses when the creep temperature is much higher than the coating's DBTT [71,72]. However, coating should not be treated as completely loading-free part before cracks form in the coating even the temperature is above the DBTT, according to [73]. It was also reported that superalloys and MCrAlY alloys showed better creep resistance when tested in air than in vacuum [74,75], which was explained by that the effective stress sustained by the sample decreased due to the beneficial friction stress due to the surface oxide layer [75]. The oxidation was also considered to be beneficial to blunt the surface pores [74] and cracks [75] and thus reduced stress concentration in those defects.

\subsubsection{Fatigue}

The hot components also sustain cyclic mechanical loads, i.e. fatigue, during the operation of turbine engines. At least three types of fatigue are widely investigated: low cycle fatigue (LCF), high cycle fatigue (HCF) and thermal mechanical fatigue (TMF).

LCF originates from, for instance, the sudden start-up and stop of an engine, while HCF occurs during the running of the engine with inevitable fluctuations [4]. The stress amplitude of LCF is usually at or beyond the elastic limit of materials, thus giving very short lifetime, often under $10^{5}$ cycles. The fatigue lifetime is usually beyond $10^{5}$ cycles in HCF in which the stress amplitude is in the elastic range with plastic deformation only occurring locally [4]. The fatigue curve or S-N curve usually has an "L" shape as shown in Fig. 9, where a fatigue limit is generally the stress value under which the fatigue life is above $10^{7}$ cycles [76]. 


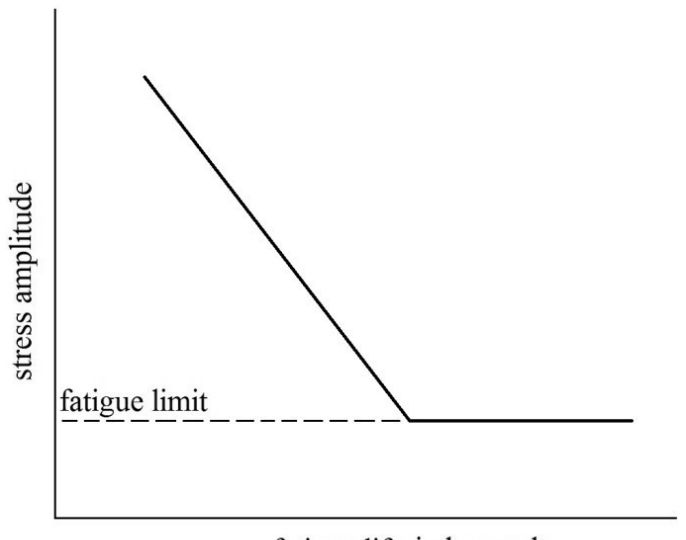

fatigue life in log scale

Figure 9. Schematic drawing of fatigue curve (S-N curve), based on [76].[76]

The application of metallic coatings seems to have no negative effect on the LCF of superalloys when the experimental temperature is above the DBTT of the coating and when the coating thickness is below a certain value [77,78]. PtAl coatings may reduce the HCF endurance limit of the coated samples by switching the crack initiation from internal pores towards in the coating or at the coating-substrate interface $[79,80]$. However, the ductility of aluminide diffusion coatings is sensitive to their thickness, especially when the thickness is smaller than $100 \mu \mathrm{m}$ [81]. Cracks may be produced in protective coatings due to mechanical bending or thermal shock [82]. Increasing the coating thickness or fatigue stress amplitude can raise the stress intensity beyond the threshold value of the substrate material $[68,83]$, making the coating cracks propagate inwards to the substrate.

During the heating-cooling process in hot sections in gas turbines, components may experience both temperature and mechanical-loading changes inducing TMF. The temperature change causes thermal fatigue stresses produced due to the difference of thermal expansion coefficients between two materials. Zhang's research [84] showed that in TMF process, diffusion coating did not produce cracks, but MCrAlY coating, as either overlay or bond coat in TBCs, could be cracked in the compression stage. In out-phase TMF a reduced lifetime due to the application of MCrAlY coating was also reported by Okazaki [78]. Zhang [84] explained that the surface rumpling of MCrAlY coating during TMF was responsible for the crack initiation. This was agreed by Tzimas [85] who found crack initiation at valley position at rumpling coating surface. Finite-element simulation showed that a large tensile stress in the oxide scale, developed during TMF, was responsible for surface crack initiation [85]. The TMF behavior of MCrAlY coatings can be improved by composition modification. For instance, the addition of Re to MCrAlY can increase the TMF lifetime $[25,86]$. 


\subsection{Chemical interactions}

The chemical interactions mean the interdiffusion of alloying elements through the coatingsubstrate interface (CSI), and the corresponding microstructural evolutions due to the interdiffusion. Such microstructural changes at the CSI may affect the mechanical behavior of the coating-substrate system.

For most MCrAlY coatings to form alumina scale against high-temperature oxidation, their $\mathrm{Al}$ content is important for an effective coating life. Al is largely consumed due to the oxidation at the coating surface at high temperature, besides which Al can be also highly consumed due to an inward diffusion of $\mathrm{Al}$ from the coating to the substrate. The interdiffusion of alloying elements through the CSI can cause local microstructural changes. Such microstructural evolution near CSI is dependent on coating composition, substrate composition and temperature.

The interdiffusion behavior of alloying elements in a diffusion couple can be investigated with the help of phase diagrams. Some representative research work can be found in [87-89]. "Diffusion path" [89] is an approach to understand the diffusion behavior of alloying elements in a diffusion couple (two different alloy contact each other). Fig. 10a schematically shows a diffusion path ("A" to " $\mathrm{B}$ ") in a ternary phase diagram, corresponding to the developed microstructure in the diffusion couple (Fig. 10b). For multicomponent alloys, like a MCrAlY coating-superalloy system, the "diffusion path" approach becomes difficult to use. To investigate the interdiffusion behavior in such systems, a number of experiments and diffusion models have been developed in recent decades [90-95].
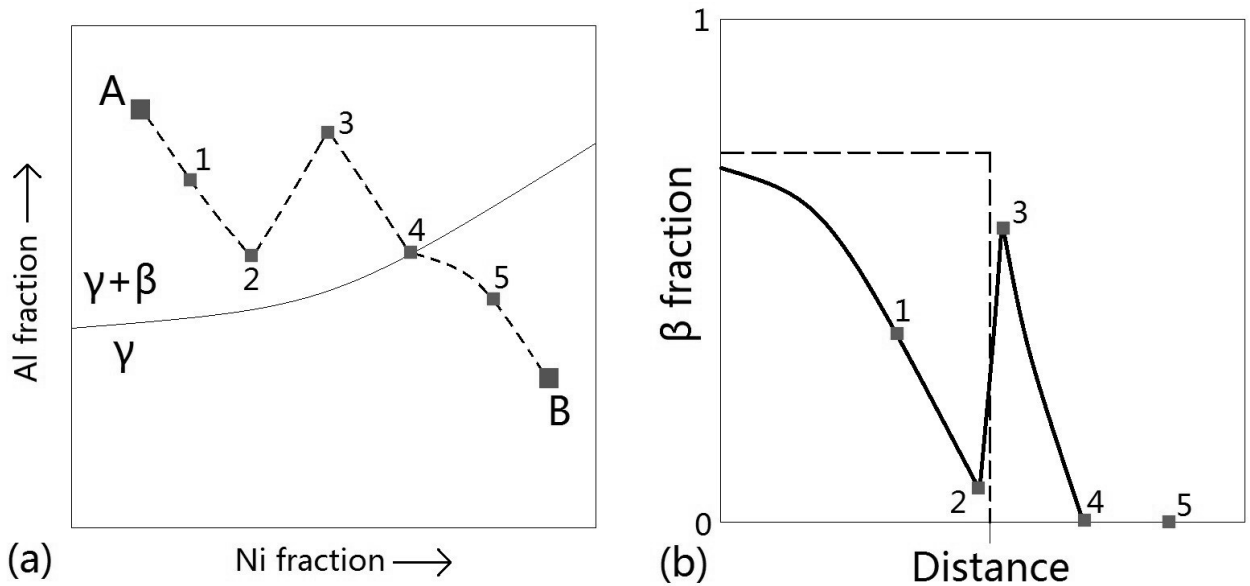

Figure 10. Composition and microstructural evolution study by using "diffusion path" approach. (a) A diffusion path (dashed line) between an A-B diffusion couple in a NiCrAl phase diagram containing $\gamma+\beta$ and $\gamma$ fields. (b) Fraction profile of the $\beta$ phase in the A-B diffusion couple (dash line for time $=$ zero, and solid curve for after the interdiffusion). The red squares in figure (a) are corresponding to the squares with the same number in figure (b). The drawings are based on the research by Engström [89]. 


\section{5 \\ Modelling}

\subsection{Thermodynamic calculations}

The thermodynamic calculations are done by using ThermoCalc software in this project. Fig. 11a shows a calculation result of the microstructure in the coating Ni-28Co- $15 \mathrm{Cr}-11 \mathrm{Al}-0.4 \mathrm{Si}-0.5 \mathrm{Ta}$ under equilibrium at high temperatures. According to the results, the stable phases in the range from $800{ }^{\circ} \mathrm{C}$ up to melting point are $\gamma$ and $\beta$ in such coating. The cross section in the MCrAlY coating with the similar composition is presented in Fig. $7 \mathrm{~b}$, showing a $\gamma+\beta$ microstructure (after the heat treatment given in Table 1). The microstructure of MCrAlY coatings varies depending on temperature and coating composition [96,97]. For Ni-Co-Cr-Al system, the phase diagrams in Fig 12 may help to predict the microstructure in a MCrAlY coating.
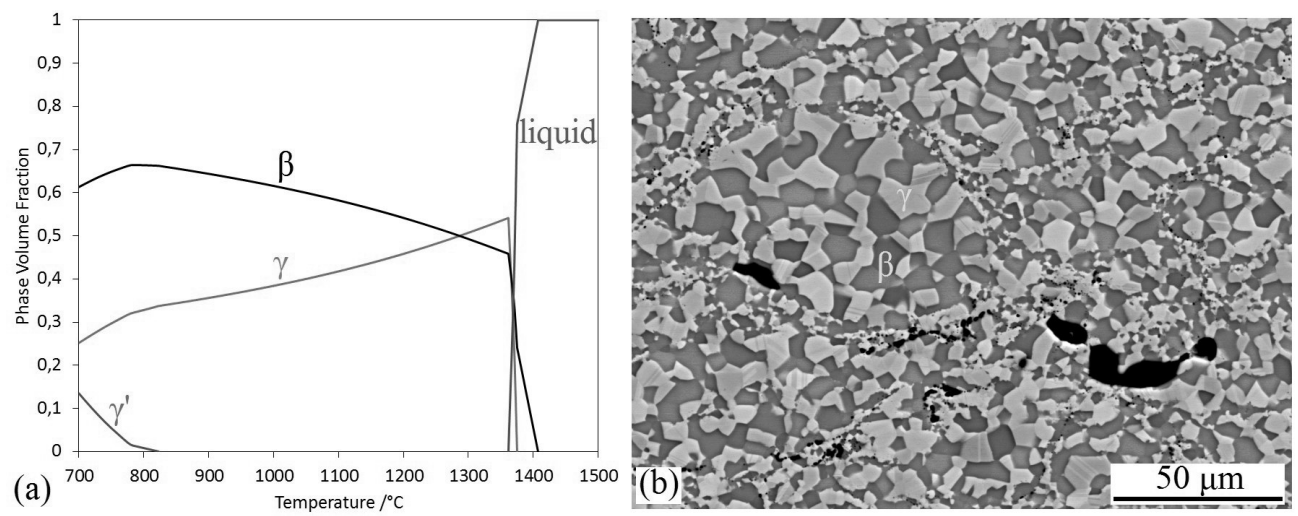

Figure 11. (a) ThermoCalc calculation of the phase volume fraction at different temperatures under equilibrium. The composition used is $\mathrm{Ni}-28 \mathrm{Co}-15 \mathrm{Cr}-11 \mathrm{Al}-0.4 \mathrm{Si}-0.5 \mathrm{Ta}$, by wt.\% (database used is TCNI6). (b) Microstructures in a MCrAlY coating after the solution and ageing heat treatment (Table 1): the grey phase is $\beta$, the light phase is $\gamma$, and the dark phase is oxides or pores). 

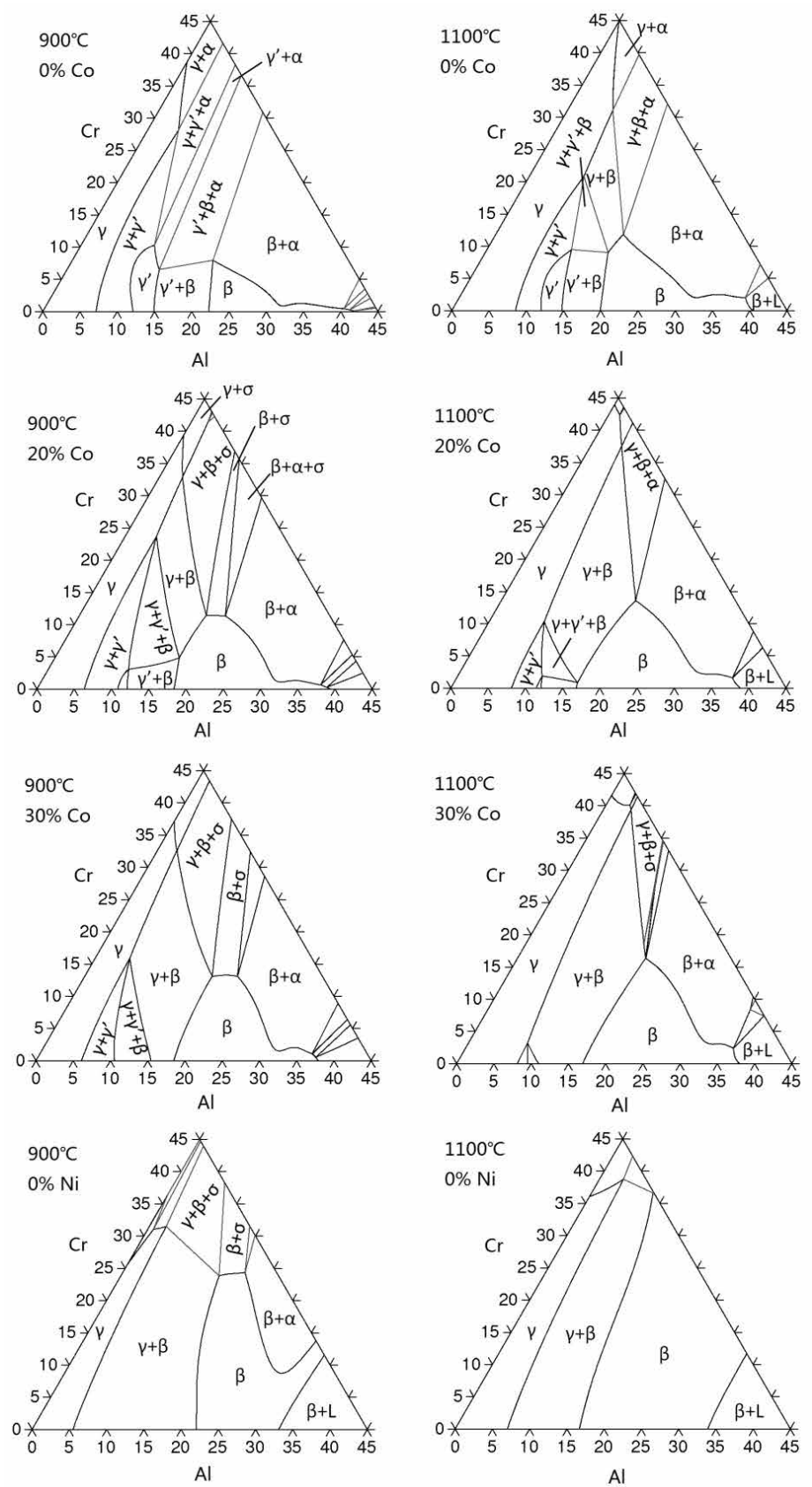

Figure 12. Phase diagrams for NiCoCrAl alloys calculated by Thermo-Calc software. 


\subsection{Oxidation-diffusion modelling}

\subsubsection{Background of modelling}

In a oxidation process, the effective coating life is determined by the degree of $\mathrm{Al}$ depletion due to Al-oxidation at the coating surface and Al-diffusion towards the substrate [24,46-49,91]. The Al depletion in a coating is schematically illustrated in Fig. 13a, and the diffusion-induced microstructural evolution in the coating is shown in Fig. 13b. The oxidation of Al promotes the formation of an outer- $\beta$-depletion zone (OBDZ) while the diffusion of $\mathrm{Al}$ from the coating to the substrate causes an inner- $\beta$-depletion zone (IBDZ). The middle part of the coating where the $\beta$ phase still exists is named the $\beta$-left zone (BLZ).
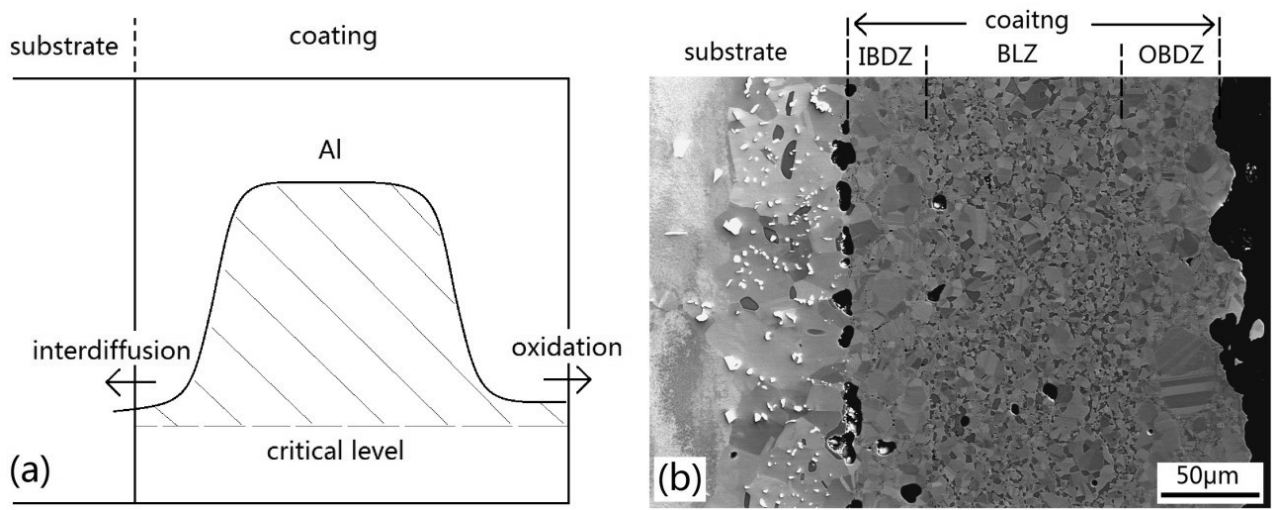

Figure 13. (a) Schematical drawing of the depletion of $\mathrm{Al}$ in the coating. (b) Microstructure degradation of a CoNiCrAlYSi overlay coating after isothermal oxidation at $1100{ }^{\circ} \mathrm{C}$ for 50 hours. The outer- $\beta$-depletion zone (OBDZ), inner- $\beta$-depleted zone (IBDZ), and $\beta$-left zone (BLZ) are formed in the coating.

Modelling on $\mathrm{Al}$ depletion in the coating took a long journey in history. An earlier oxidation model in a NiCrAlZr coating on a Ni-base substrate was established by Nesbitt et al. [98] whose results showed a good agreement of the predicted $\mathrm{Al}$ concentration with their experimental result but only during short stages of the coating life. By taking into account of varying oxidation kinetics, Nijdam et al. [99] devised a more complex oxidation model which showed a reasonable agreement with experimental concentration profiles in a single- $\gamma \mathrm{NiCrAl}$ alloy. With furtherdeveloped thermodynamic and kinetic databases, the microstructural evolution can be predicted by choosing suitable diffusion models in DICTRA software [100]. One successful example was the attempt by Nijdam and Sloof [101] who modeled the $\beta$-depletion due to isothermal and cyclic oxidation in a freestanding MCrAlY alloy.

In this project, we created an oxidation-diffusion model by combining DICTRA software and Matlab, to simulate the diffusion of alloying elements and the microstructural evolutions in coating-superalloy systems in high-temperature oxidation process [94,95,102,103]. 


\subsubsection{Setting-up of the model}

The oxidation-diffusion model built in this project has been applied in several research work $[94,95,102,103]$; the model procedures for four different conditions are outlined in Fig. 14. The procedure in (a) considers the surface oxidation and the interdiffusion of alloying elements through the coating-substrate interface. The procedure in (b) further includes the oxidation inside of the coating. In (c), diffusion blocking effect is also integrated into the oxidation-diffusion model. The procedure in $(\mathrm{d})$ takes internal oxidation and nitridation into account in a superalloy.

The reason to take the diffusion blocking effect into account in the procedure in (c) is that diffusion blocking effect was indeed observed in some thermally sprayed coatings (APS, HVOF etc.). Brandl W. et al. [104] claimed that the presence of the finely distributed alumina might hinder the diffusion of the alloying elements along grain boundaries in a HVOF coating during oxidation. The idea of diffusion blocking by the dispersed oxides was also put forward by Peng $\mathrm{H}$. [105] whose results showed a decreased oxidation rate by doping fine alumina into a MCrAlY coating. Fossati [106] performed a pre-oxidation on MCrAlY powders and found that MCrAlY coatings by using such powders showed a lower oxidation rate. By taking the splat-to-splat structures as some isolated diffusion cells, Evans et al. [107] established a model to simulate the chemical failure due to oxidation and diffusion in the plasma-sprayed coating. For the procedure in Fig. 14c, the diffusion blocking effect is simply simulated by setting different diffusion times in the coating and the substrate.

In those models, the coating-substrate couple or the single superalloy (or single coating) is represented in $2 \mathrm{D}$ by a set of nodes in which the local composition is stored. The diffusion of alloying elements in the coating-substrate system is simulated by DICTRA software, while the oxidation (and nitridation) rate is controlled by using Matlab. The procedures in the model are performed by iterating several steps:

- Removal of oxidized amount of the element(s) from the particular nodes in the coating (done by Matlab). For instance if only surface oxidation (of $\mathrm{Al}$ ) is considered, $\mathrm{Al}$ is removed from the outmost nodes of the coating. The oxidation rate is described by a power equation:

$$
h=h_{0}+(k t)^{1 / n}
$$

where $h$ is the oxide scale thickness, $h_{0}$ the scale thickness before the oxidation, $k$ the oxidation constant, $t$ the time, and $n$ the oxidation exponent.

- Diffusion simulation by using the DICTRA software. There are several diffusion models available in DICTRA software, like "the homogenization model (about 10 varieties)", "the disperse model", and "the grain-boundary model", which are possible to be used for calculating the diffusion of alloying elements in the oxidation-diffusion model. However, from the author's experience, the homogenization model is the most friendly model and was adapted in our publications $[94,95,102,103]$. In (a), (b) and (d), the diffusion is done through the whole material. However, for the procedure in (c) which considers diffusion 
blocking effect (inside of the coating and at the coating-substrate interface), the diffusion blocking effect is simulated by separately running the diffusion in substrate and coating.

- The composition profile produced after each step in the procedures is used as the input data for the next step.

(a)
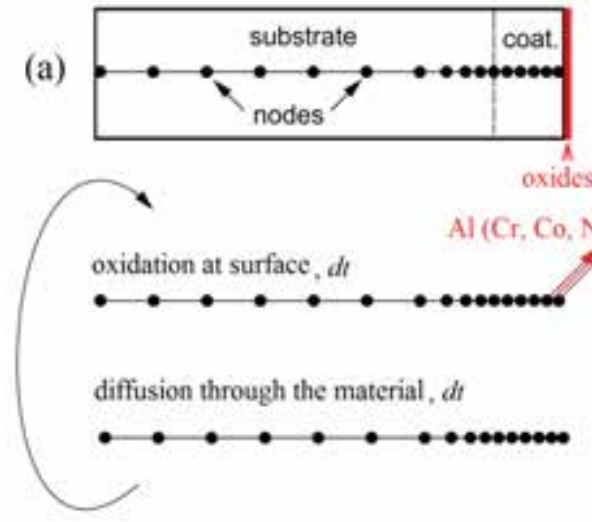

(c)
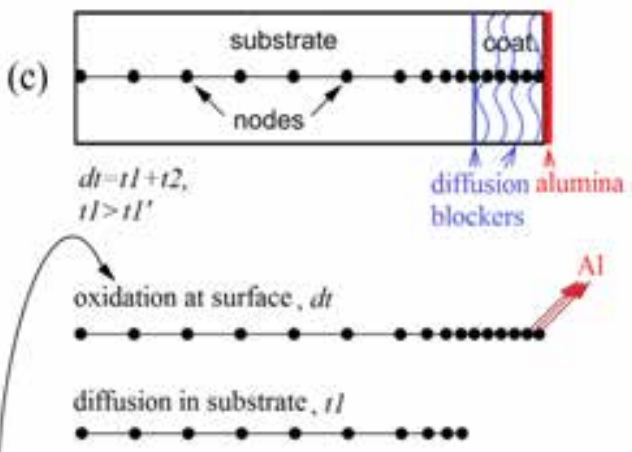

diffusion in coating, $t I^{\prime}$

๑04060

diffusion through the material , $t 2$

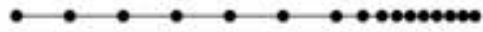

(b)
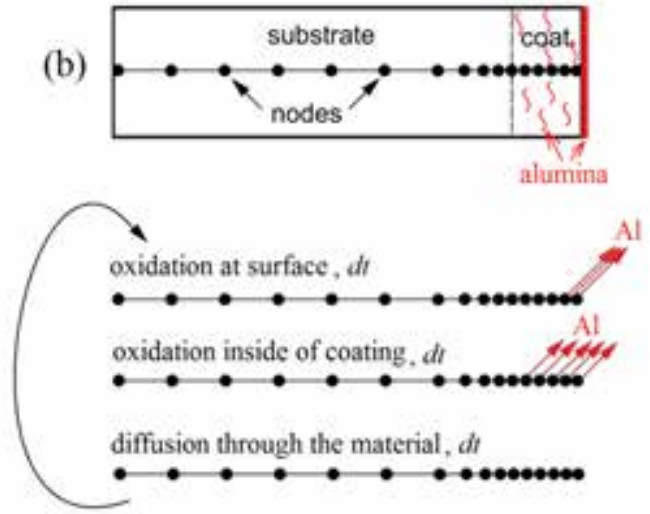

(d)
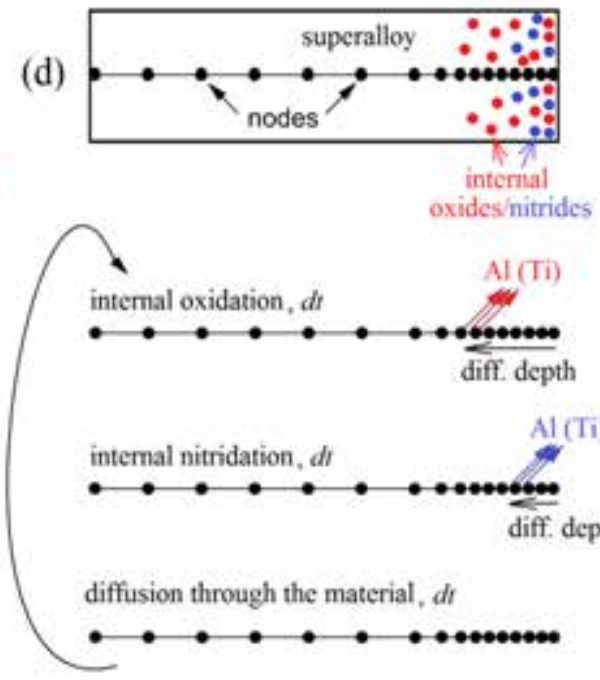

Figure 14. The different procedures for the oxidation-diffusion model: (a) considering surface oxidation, (b) considering surface and inside oxidation, (c) considering surface oxidation and diffusion blocking effect in the coating and at the coating-substrate interface, (d) considering internal oxidation and nitridation in superalloy. 


\subsubsection{Challenges of the modelling work}

Some challenges that the oxidation-diffusion model faces are:

- Oxidation law. So far, the oxidation of alloying elements (e.g. Al) is only done by using a simple power equation to fit the experimental measurement of the oxide thickness. It will be more interesting and useful if formation of the oxides can be automatically integrated in DICTRA. To do that, the diffusion of oxygen in alloys should be integrated, as well as the thermodynamic data of the oxides and the diffusivity of the elements in the oxides.

- Limitation of the database. The Ni-based database used in the current work is developed mainly for Ni-based alloys. There are indeed more mismatches between the simulation and experiments when modelling a Co-based alloy system.

- Temperature. So far, the simulations by DICTRA are only for isothermal cases. However, in reality, for instance in a TBC + cooling system, a temperature gradient exists through the whole material system, then the temperature gradient should be considered. 


\section{6 \\ Methods}

\subsection{Spray of MCrAlX coatings}

In this project, the MCrAlX coatings were manufactured by high-velocity oxy-fuel spraying (HVOF). The HVOF process is schematically shown in Fig. 15, which consists of feeding powders with a carrier gas, mixing the powders with oxygen and fuel in the combustion chamber, and spraying the powders in a high velocity. The HVOF spraying stream which contains semimolten powder particles will impact the surface of the target material to form a coating layer. The nominal compositions of the coatings which were spayed by HVOF in this project are shown in Table 6. The HVOF coatings have a typical splat-to-splat structure as shown in Fig. 16. The black features in the coating are pores or cracks which can be largely reduced by performing the solution and ageing heat treatment (Table 1).

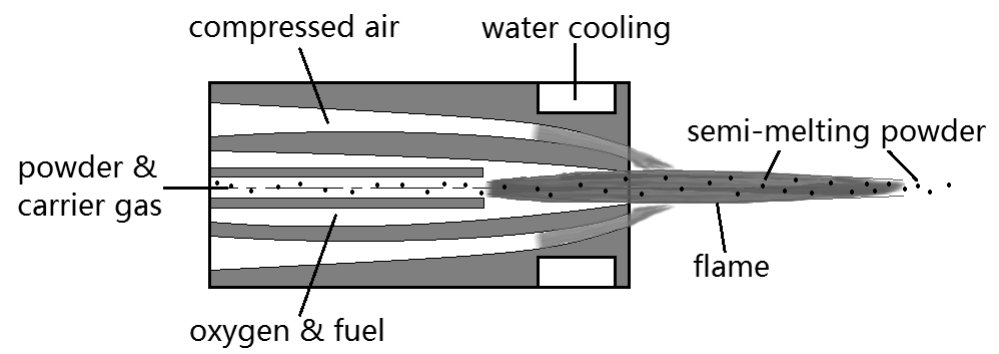

Figure 15. Schematic drawing of HVOF spraying process.

Table 6. Nominal compositions of some MCrAlX coatings designed in the project.

\begin{tabular}{cccccc}
\hline & $\mathrm{Ni}$ & $\mathrm{Co}$ & $\mathrm{Cr}$ & $\mathrm{Al}$ & $\mathrm{X}$ \\
\hline Ni-based & Bal. & 28 & 15 & 11 & \multirow{2}{*}{ Y, Si, Ta, Ir, Ru, Hf, Mo, et al. } \\
\hline Co-based & 30 & Bal. & 20 & 10 & \\
\hline
\end{tabular}



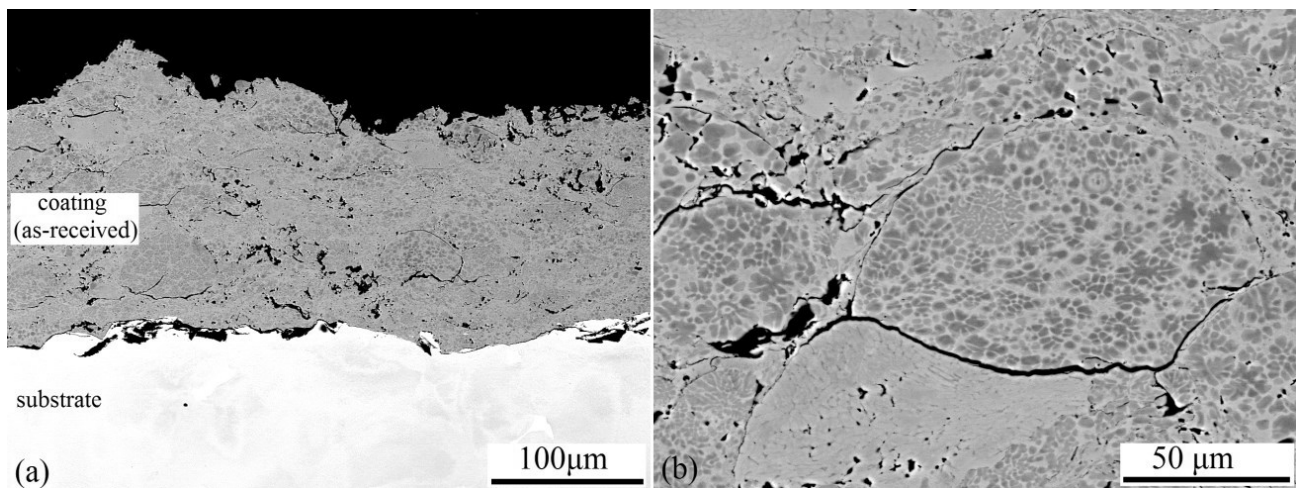

Figure 16. Cross section of an as-received MCrAlY coating by HVOF spraying (a) overview, (b) a magnified image showing the splats, cracks and voids.

\subsection{Oxidation and hot corrosion testing}

In this project, oxidation tests were carried out in in air either at a constant temperature (namely isothermal oxidation, at 900,1000 , and $1100{ }^{\circ} \mathrm{C}$ ) or at a cyclic temperature (namely thermal cycling fatigue, heating at $1100{ }^{\circ} \mathrm{C}$ for $1 \mathrm{~h}$ and a $10 \mathrm{~min}$ compressed-air cooling to about $100^{\circ} \mathrm{C}$ ). The furnaces used for these tests are shown in Fig. 17. In particular, compressed-air cooling system was applied to cool the hot samples in the thermal cyclic furnace (Fig. 17b). All the oxidation testing on the MCrAlX coatings presented in this thesis was done in Siemens Industrial Turbomachinery AB, in Finspång (Sweden).
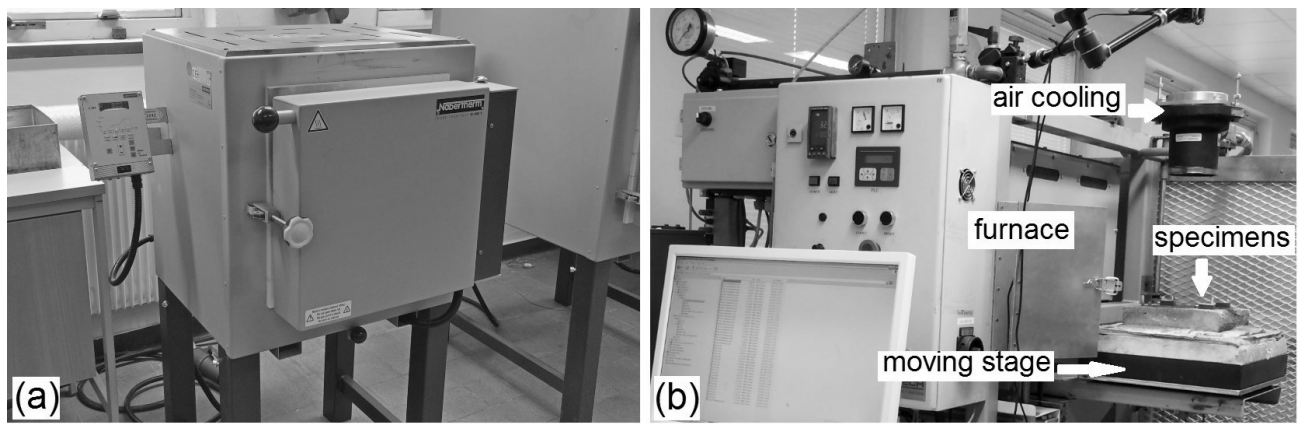

Figure 17. The furnaces used for high-temperature oxidation testing: (a) for isothermal oxidation, and (b) for thermal cyclic fatigue. Both tests were done at Siemens Industrial Turbomachinery $\mathrm{AB}$ (Finspång). 

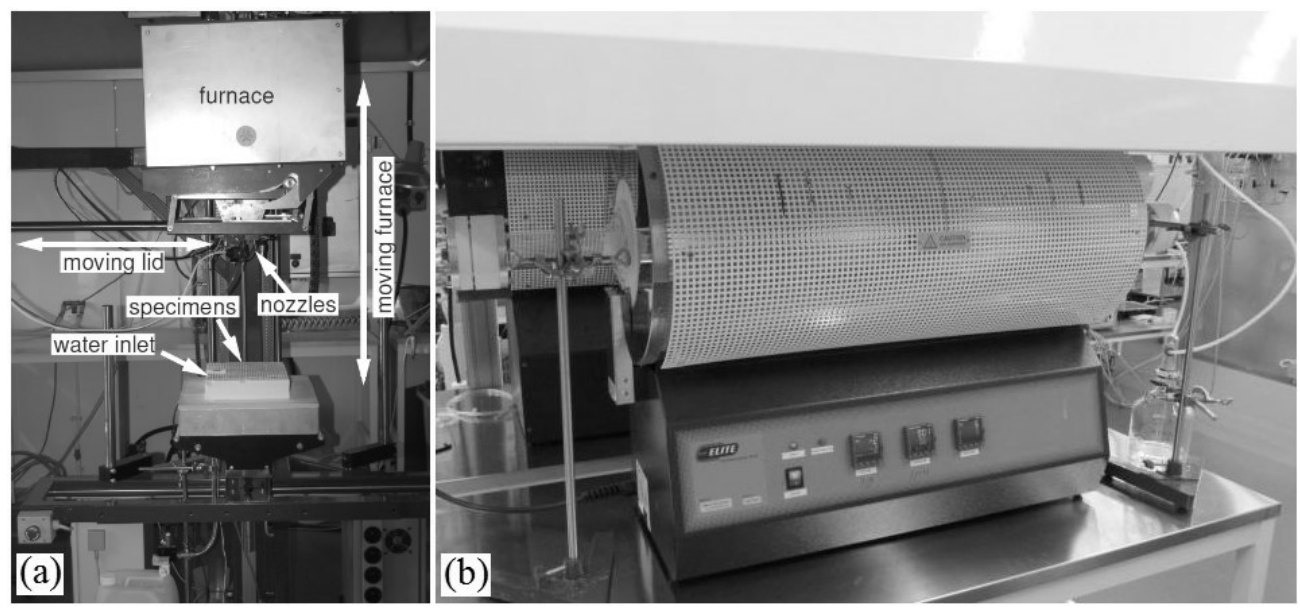

Figure 18. The furnaces used for the cyclic corrosion testing. (a) box rig used in Linköping University (Sweden) for the SD condition, (b) tube rig used in KIMAB (Sweden) for the SA and SS conditions.

Cyclic corrosion testing was done in three different environments: salt deposition (SD), $\mathrm{SO}_{2}$ in air (SA), and salt with $\mathrm{SO}_{2}$ (SA). The testing temperature was held at $900{ }^{\circ} \mathrm{C}$ for 48 hour per cycle; before each cycle, water solution containing $(0.8 \mathrm{Na}, 0.2 \mathrm{~K})_{2} \mathrm{SO}_{4}$ was sprayed onto the sample surfaces to assure an about $25 \mu \mathrm{g} /\left(\mathrm{cm}^{2} \cdot \mathrm{h}\right)$ coverage of the salt (for the SD and SS conditions). The SD corrosion was done in a box rig, as shown in Fig. 18a. In the SA and SS conditions, 500 ppm $\mathrm{SO}_{2}$ with air flew through in the tube rig (Fig. 18b) during the corrosion at $900{ }^{\circ} \mathrm{C}$.

\subsection{Thermodynamic and kinetic simulations}

Thermodynamic calculation is done by using ThermoCalc software. The software is used mainly for thermal equilibrium calculations based on the Calphad spirit. The calculations are dependent on the accuracy of the database applied. To achieve a simulation in Ni or Co based alloys like superalloys and high-temperature metallic coatings, Ni-based database was used (the lasted version, by the summer 2014, is TCNI6).

DICTRA was used to simulate diffusions in materials. For the diffusion in a MCrAlY-superalloy system, the basic DICTRA programs can be described as follows. Firstly, the software reads in the suitable databases. Chemical elements, temperature, and pressure should be clarified for the system. Then, a 2D "region" can be set up with a distribution of nodes for numerical calculations. In each node, there stores the local composition and corresponding thermodynamic and kinetic parameters. Then a global or boundary condition should be claimed for the "region". Finally, run the program. 

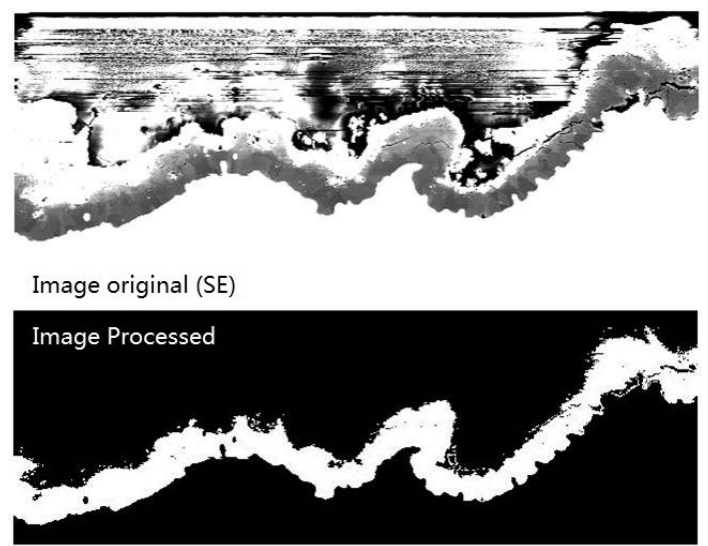

Figure 19. Imaging analysis to obtain the amount of alumina at coating surface.

In this research, to simulate the diffusion of alloying elements in the multiphase material system, a homogenization model was used. There are several bounds available under different hypotheses on how different phases react for the diffusion of elements between the phases. The one which was used often in this project is "upper Wiener bounds" or called "Rule of mixtures", by taking the diffusion of $\mathrm{Al}$ as an example, which is described by $\sigma_{A l}^{e f f}=\sum f^{i} \sigma_{A l}^{i}$, where $\sigma_{A l}^{\text {eff }}$ is the effective transport parameter of $\mathrm{Al}, f^{i}$ is the fraction of phase $i, \sigma_{A l}^{i}$ is the transport parameter of Al in the phase $i$. The so-called transport parameter $\sigma_{A l}^{i}=\left[M_{A l}^{i} x_{A l}^{i}\right]$, where $M_{A l}^{i}$ is the mobility of $\mathrm{Al}$ in phase $i, x_{A l}^{i}$ is the concentration of $\mathrm{Al}$ in the phase $i$.

Due to lack of database for oxides, the DICTRA software can not be used for a direct oxidation simulation yet (by the summer 2014). To integrate an oxidation process, the oxidation law has to be forced into the model in Fig. 14, as explained in the chapter "5.2.2". The oxidation rate of an element (usually $\mathrm{Al}$ ) needs a measurement of the oxide thickness by an imaging analysis as shown in Fig 19.

\subsection{Microscopy}

A field-emission gun scanning-electron microscope (FEG-SEM) was used for the analyses of microstructure, crystalline structure of phases, and chemical composition in materials. There are two modes for imaging the microstructures in this SEM: secondary electron (SE) mode and backscattered electron (BSE) mode. SE mode is good at imaging the morphology of sample surface; BSE mode has a lower depth resolution but is sensitive to plastic deformation or chemical variation (i.e. elemental contrast). By tilting the sample surface to around $70^{\circ}$, the crystalline information in materials can be studied by using electron backscattered diffraction (EBSD) technique. Microanalysis of chemical compositions can be also performed in the SEM. With the interaction between the electron beam and samples, X-rays are emitted, and can be captured and analyzed by energy or wavelength dispersive spectroscopes (EDS or WDS). Fig. 20 shows an example to identify $\beta, \gamma, \gamma^{\prime}$ phases by combining EBSD and EDS. 

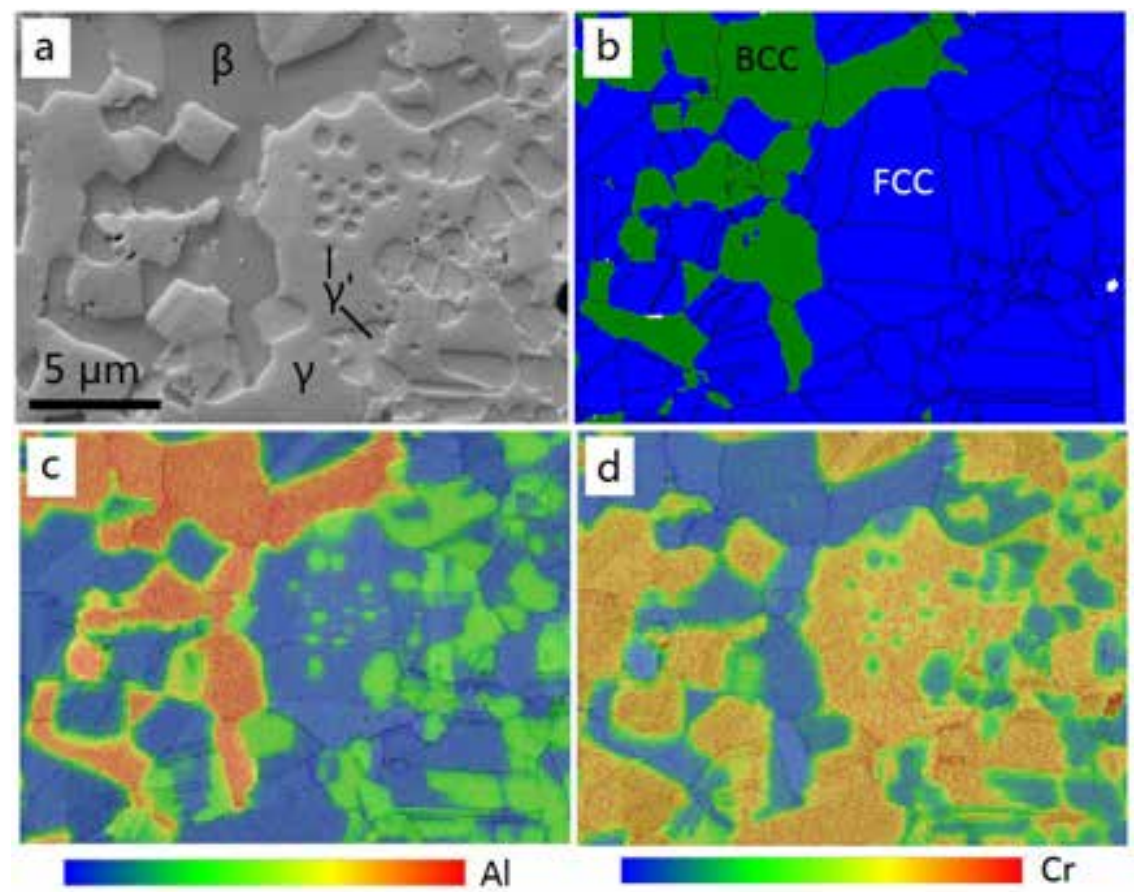

Figure 20. Phase identification by combining EBSD and EDS. (a) SEM image, (b) EBSD image (green for BCC phases, blue for FCC phases), (c) EDS mapping of $\mathrm{Al}$, (d) EDS mapping of $\mathrm{Cr}$. $\beta$ phase is $\mathrm{BCC}, \mathrm{Al}$ rich and $\mathrm{Cr}$ poor, $\gamma$ phase is $\mathrm{FCC}, \mathrm{Al}$ poor and $\mathrm{Cr}$ rich, $\gamma$ ' phase is $\mathrm{FCC}, \mathrm{Al}$ medium and $\mathrm{Cr}$ poor.

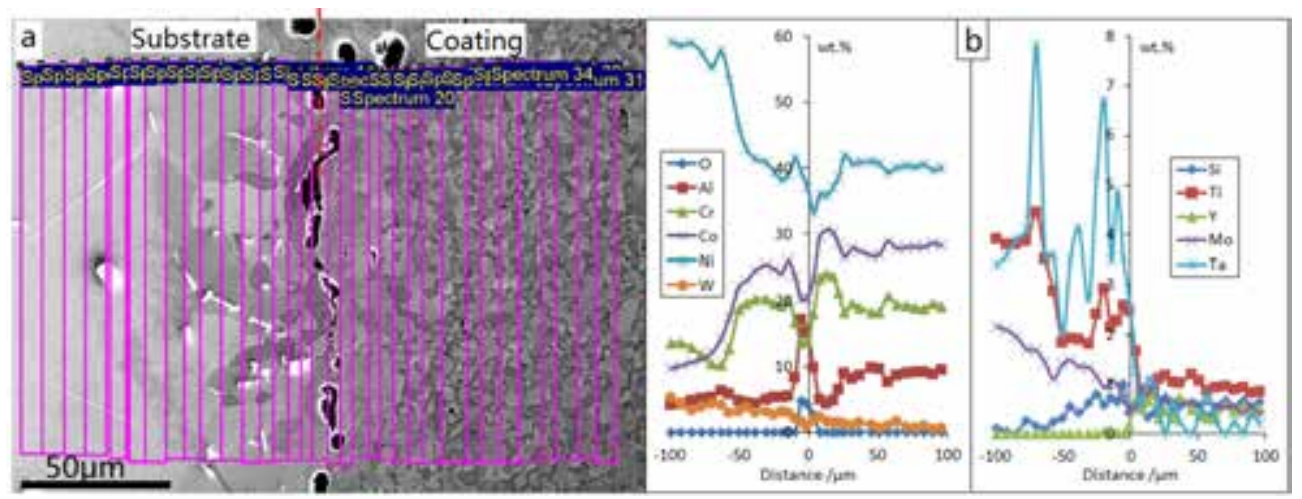

Figure 21. Stripping EDS measurement to obtain the composition profiles through the material. The composition in each strip is an average value in the stripped square. The CSI is set as distance $=0$. 
When quantitatively measuring the chemical compositions in material, EDS is used. Firstly, a pure Co standard is used to correct the SEM machine parameters. Then, the composition of the interested point or area in the sample will be measured. Fig. 21a gives an example on how a composition profile cross a coating-substrate interface is measured. The composition at a particular distance is an average of the composition in the stripped square. The compositions in such strip-by-strip measurement form a profile as presented in Fig. $21 \mathrm{~b}$.

\subsection{Other tests}

Some mechanical measurements were also performed on the HVOF coatings, namely adhesion test and micro-hardness measurement. Those tests could provide some information for understanding the creep or fatigue properties of those coatings in next research step of this project.

The adhesion test was done on a tensile machine, on which the one-side coated button sample was glued to two bars which would be loaded until fracture. All the tested samples were fractured at coating-glue interface or through the glue (FM-1000), meaning that the adhesion strength of the coating-substrate interface was stronger than the glue strength, which was believed to be beyond the industrial requirement for operation.

Micro hardness was another value representing the coating quality and coating strength. In this project, the micro hardness of the coatings, after the solution and ageing heat treatment (Table I), should be similar as the substrate to have a good mechanical match with the substrate. Fig. 22 provides the results showing the comparison of Vickers hardness of some developed MCrAlY coatings against the substrate (Inconel 792). The variation of the hardness values among the coatings was mainly due to the coating composition and microstructures. For instance, the Cobased MCrAlX coatings were $\mathrm{Cr}$ rich and formed some $\sigma$-phases and $\alpha$-Cr phases after the heat treatment, which caused a higher hardness of those coatings.

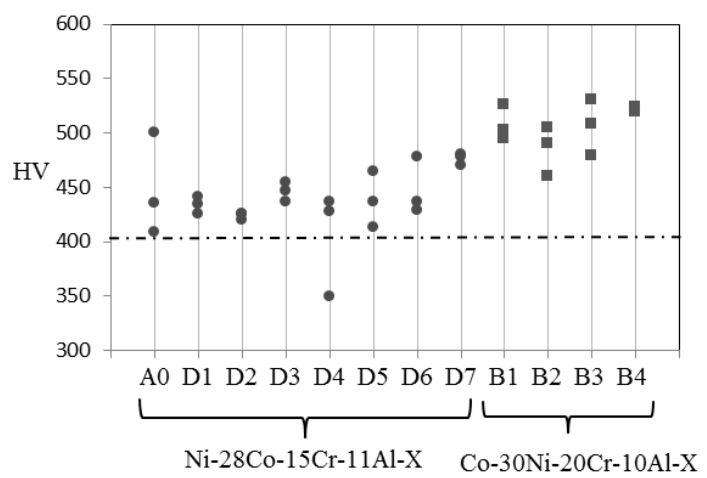

Figure 22. The Vickers micro hardness of HVOF coatings after the heat treatment in Table 1. The dotdash line is for the substrate Inconel 792. 


\section{Summary of Appended Papers}

\section{Paper I: Modeling of microstructural evolution and lifetime prediction of MCrAlY coatings on nickel based superalloys during high temperature oxidation}

At high temperature, oxidation occurs at MCrAlY coating surface. Simultaneously, diffusion of alloying elements in the coating-superalloy system also takes place, which drives the microstructural evolution during the oxidation process. The aim of this paper is to develop an oxidation-diffusion model for MCrAlY coating-superalloy system, to simulate the microstructural changes in the material and to provide a microstructure-based lifetime-prediction approach.

A cobalt based MCrAlY coating was sprayed onto a nickel based superalloy Inconel 792 by using high-velocity oxy-fuel (HVOF) technique. The HVOF coatings had about $200 \mu \mathrm{m}$ thickness, with a typical splat-on-splat microstructure. The coatings were subjected to a solution and ageing heat treatment before oxidation testing. The oxidation testing was performed at three temperatures 900, 1000 and $1100{ }^{\circ} \mathrm{C}$. Samples, from different oxidation times, were cross-sectioned for microstructure and chemical-composition analyses.

The oxidation-diffusion model was built by integrating DICTRA and Matlab software. In the model, the coating-superalloy couple was represented in 2D by a set of nodes in which the local composition is stored. DICTRA was used to simulate the diffusion of alloying elements as well as the microstructural changes. The effective diffusivities of the alloying elements were calculated by using a "rule-of-mixture" for the multi-phase material system. Matlab was used to remove the $\mathrm{Al}$ content from the $2 \mathrm{D}$ nodes near the coating surface according to an experimentally-measured oxidation law. To increase the accuracy of the modelling for the HVOF coating, diffusion-blocking effects were also integrated by manipulating the diffusion times in the coating part and the substrate part. The diffusion blockers were the small oxides along the splats' interfaces in the coating, and the pores and alumina grits at the coating-substrate interface.

The MCrAlY coating had a typical $\gamma+\beta$ microstructure while the substrate had a $\gamma+\gamma$ ' structure. At a low temperature $\left(900{ }^{\circ} \mathrm{C}\right), \sigma$ phase also formed in the coating. Due to the oxidation at the coating surface, mainly an oxidation of Al, an outer- $\beta$-depletion zone (OBDZ) was formed. Due to the inward diffusion of $\mathrm{Al}$ from the coating to the substrate, an inner- $\beta$-depletion zone (IBDZ) 
also formed. The oxidation-diffusion model can well predict the $\beta$ depletion rate at those temperatures. The coating life, when the $\beta$ phase in the coating was totally depleted, predicted by the model was about 300 hours at $1100{ }^{\circ} \mathrm{C}$, which agreed very well with the experiment. The lifetimes of the coating at $1000{ }^{\circ} \mathrm{C}$ and $900{ }^{\circ} \mathrm{C}$ were predicted as about 3000 hours and $>10,000$ hours, respectively. The development of the composition profiles of the alloying elements in the material system was also well captured by the model. The results inspirited a further application of the model onto microstructure modelling and life prediction of MCrAlY coatings.

\section{Paper II: MCrAlY coating design based on oxidation-diffusion modelling. Part I: Microstructural evolution}

This paper applied the oxidation-diffusion model in different combinations of superalloys and MCrAlY coatings ( $1 \mathrm{~mm}$ thick substrate, $150 \mu \mathrm{m}$ thick coating). The aim of this work was to study the influence of coating composition, substrate composition and temperature on the microstructural evolution in MCrAlY coating-superalloy systems in high-temperature oxidation.

Two substrates with simplified composition (wt.\%) were used in the model: Ni-15Cr-5Co-0.5Al (s1), to represent typical wrought superalloys, and $\mathrm{Ni}-15 \mathrm{Cr}-15 \mathrm{Co}-5 \mathrm{Al}-4 \mathrm{Ti}$ (s2) to represent typical cast superalloys. The compositions of MCrAlY coatings were the combinations of $\mathrm{Ni}$ (balanced), $\mathrm{Co}$ ( 20 or $40 \%), \mathrm{Cr}$ (15 or $25 \%$ ), and $\mathrm{Al}$ (6 or $13 \%)$. Oxidation laws were obtained by collecting data from the literature in the temperature range between 800 and $1200{ }^{\circ} \mathrm{C}$.

The modelling results showed that increasing the content of $\mathrm{Al}, \mathrm{Co}$ and/or $\mathrm{Cr}$ stabilized the $\beta$ phase in coatings. The coating life, when the $\beta$ phase in the coating was totally depleted, can be prolonged more than five times when increasing the Al content in the coating from 6 to $13 \mathrm{wt} . \%$. The coating life can be increased by around one order of magnitude if the temperature was reduced by $100^{\circ} \mathrm{C}$. Decreasing temperature can also promote a $\beta \rightarrow \gamma^{\prime}$ transition when the $\beta$ phase was depleted in the coating while at a higher temperature the $\beta \rightarrow \gamma$ transformation was preferred.

In the $\gamma+\gamma^{\prime}$ superalloy (s2), $\gamma^{\prime}$ can be depleted from the coating-superalloy interface due to the inward diffusion of $\mathrm{Co}$ and $\mathrm{Cr}$ from the coating; higher $\mathrm{Co}$ and $\mathrm{Cr}$ contents in the coating produced larger depletion depths of $\gamma^{\prime}$ in the superalloy. With the $\gamma^{\prime}$ depletion in the superalloy, $\gamma$ or $\gamma+\beta$ zone formed; the $\beta$ phase formed in the superalloy was called secondary $\beta$ phase. The formation of the secondary $\beta$ phase and the depletion of $\gamma^{\prime}$ in the superalloy can be suppressed if the contents of $\mathrm{Co}, \mathrm{Cr}$ and $\mathrm{Al}$ in the coating were low, or a low-Al substrate (s1) was used.

\section{Paper III: MCrAlY coating design based on oxidation-diffusion modelling. Part II: Lifing aspects}

This paper is the second part of Paper II, focusing on the coating-life prediction by three criteria $\beta$ depletion (C1), Al depletion (C2), and critical TGO thickness (C3). 
$C 1$ is a microstructure based criterion, which describes the coating life when the Al-rich $\beta$ phase is totally depleted in the coating. $C 2$ is the criterion that based on the $\mathrm{Al}$ concentration near the coating surface and the coating life is defined as the time when the $\mathrm{Al}$ concentration lowers down to a critical level, e.g. 2.5 or 3 wt.\%. The third criterion, $C 3$, simply uses the power laws, which was applied to describe the TGO growth rate in the oxidation-diffusion model, to calculate the time when a critical TGO thickness is reached ( 8 and $10 \mu \mathrm{m}$ was used). The content of $\mathrm{Cr}$ and $\mathrm{Co}$ in the MCrAlY coatings was represented by a so-called equivalent $\mathrm{Cr}$ content $-\mathrm{Cr}_{e}\left(\mathrm{Cr}_{e}=\mathrm{Cr}+\right.$ $0.5 \mathrm{Co})$.

The modelling results showed that at a low temperature $\left(850{ }^{\circ} \mathrm{C}\right)$, the interdiffusion of alloying elements between the coating and the substrate was low, and the depletion of $\mathrm{Al}$ from the coating to the substrate was not the key factor influencing the coating's life; instead, the oxidation was the main factor to mark the coating life. The results also showed that a lower temperature promoted $\beta$ stability, resulting in that the coating life by $C 2$ or $C 3$ would be reached first, particularly for coatings with high $\mathrm{Cr}_{e}$ that promoted the $\beta$ stability. At high temperatures (950$1050{ }^{\circ} \mathrm{C}$ ), a coating would lose considerable Al through the interdiffusion with the low $\mathrm{Al}$ substrate (s1) while a coating on the high Al substrate (s2) tended to reach a steady-state $\mathrm{Al}$ content at the coating surface as the substrate acts as an $\mathrm{Al}$ reservoir.

From the perspective of MCrAlY coating design, the modelling results suggest that a low $\mathrm{Cr}_{e}$ coating will give slower $\mathrm{Al}$ depletion through interdiffusion since $\mathrm{Al}$ activity is lower in such a coating. Different life criteria may have to be chosen according to the alloy composition.

\section{Paper IV: Simulation of oxidation-nitridation-induced microstructural degradation in a cracked Ni-based superalloy at high temperature}

The oxidation-diffusion model presented in Paper I-III was further modified by integrating the internal growth of oxides and nitrides. Substrate material Inconel 792 was used for a creep testing at $900{ }^{\circ} \mathrm{C}$ in air. The applied creep load induced cracks normal to the loading direction and the oxidation behavior of the superalloy along the cracks was investigated. The creep testing was done until the sample fractured at 680 hours.

The cross-sectional microstructure showed that at the superalloy surface, a porous chromia layer was formed at the outmost surface, followed by a $\gamma^{\prime}$ depletion zone in the alloy where some small internal alumina and TiN were formed. While along the creep cracks, AlN was also formed besides alumina and TiN. The penetration depth of the internal oxides and nitrides, in increasing order, was alumina, AIN, and TiN. The penetration depths of those oxides and nitrides in the superalloy qualitatively agreed with predictions by the Wagner's equation.

In the oxidation-diffusion model, the oxidation and nitridation laws were described by simple parabolic equations. The content of the oxides and nitrides formed in the material was measured by image analysis along the crack. The internal oxidation and nitridation of $\mathrm{Al}$ or $\mathrm{Ti}$ was simulated by removing the oxidized or nitridized content of $\mathrm{Al}$ or Ti from the nodes where the new oxides/nitrides of $\mathrm{Al}$ or $\mathrm{Ti}$ were formed during the process. The modelling results show that 
the predicted composition profiles of the alloying elements in the superalloy agreed well with the experimental measurement. The results also indicate that both the oxidation/nitridation of $\mathrm{Al}$ and the nitridation of Ti were responsible for the depletion of $\gamma^{\prime}$ in the superalloy.

\section{Paper V: Some aspects of elemental behaviour in HVOF MCrAlY coatings in high-temperature oxidation}

The aim of this study was to investigate the behavior of alloying elements (main elements like $\mathrm{Ni}$, $\mathrm{Co}, \mathrm{Cr}$ and $\mathrm{Al}$, minor elements like $\mathrm{Y}, \mathrm{Hf}, \mathrm{Ru}$ and $\mathrm{Ir}$ ) in HVOF MCrAlY coatings in hightemperature oxidation. Three oxidation temperatures were applied: 900,1000 and $1100{ }^{\circ} \mathrm{C}$. The study mainly focused on the behavior of the alloying elements in the interdiffusion between the coating and the substrate (Inconel 792, a $\gamma+\gamma$ ' superalloy) and in the oxidation at the coating surface.

The interdiffusion of alloying elements at the coating-substrate interface was mainly controlled by the main elements. Due to a higher activity of $\mathrm{Co}$ and $\mathrm{Al}$ in the coating than in the substrate, inward diffusion of $\mathrm{Co}$ and $\mathrm{Al}$ drove the microstructural evolution at the coating-substrate interface. The function of those main elements on the microstructural evolution at the coatingsubstrate interface basically agreed with the results as described in Paper II. At the coating surface, spinels were formed above an alumina scale. It was found that the crystalline structure of the spinels were temperature dependent: having $\mathrm{CoCr}_{2} \mathrm{O}_{4}$ structure at the low temperature $\left(900{ }^{\circ} \mathrm{C}\right)$, and owning $\mathrm{CoAl}_{2} \mathrm{O}_{4}$ structure at the high temperature $\left(1100{ }^{\circ} \mathrm{C}\right)$.

The minor elements like $\mathrm{Y}$ and Hf mainly affected the oxidation behavior at the coating surface. For instance, the addition of $\mathrm{Hf}(0.3 \mathrm{wt} . \%)$ caused a significantly accelerated inward growth of the alumina scales, by segregating at the grain boundaries of the alumina. Y, being oxidized, was mainly at the air-contacting side of the alumina scale, indicating that yttria may not contribute mechanically to the scale-coating interface strength but may play a role in the nucleation and the early growth of the alumina scale. Ru and Ir were mainly found to partition in the $\beta$ phase in the coating and can hardly diffuse into the $\gamma+\gamma$ ' area in substrate. Ru and Ir may have no direct effect on the oxidation behavior of the coatings, because no oxides rich of these two elements were detected at the coating surface.

\section{Paper VI: Hot corrosion behavior of MCrAlY coatings containing $\mathrm{Ru}$ and Ir}

Hot corrosion behavior of CoNiCrAlYSi(Ta) coatings with $\mathrm{Ru}(0.5$ wt.\%) or $\operatorname{Ir}(0.5$ wt.\%) was studied in 48 -hour cycles at $900{ }^{\circ} \mathrm{C}$ in an environment with deposit of $(0.8 \mathrm{Na}, 0.2 \mathrm{~K})_{2} \mathrm{SO}_{4}$.

The results showed that the oxide layer formed at the coating surface mainly consisted of alumina $\left(\alpha-\mathrm{Al}_{2} \mathrm{O}_{3}\right)$ and spinels $\left(\mathrm{CoCr}_{2} \mathrm{O}_{4}\right.$ and $\left.\mathrm{NiCr}_{2} \mathrm{O}_{4}\right)$. In such hot corrosion condition, the Al-rich oxide 
scale became an oxide mixture as the result of fluxing of the oxides. The fluxed Al-oxide scale had smaller grain size than a pure alumina formed in a lab-air oxidation. Up to the 6th cycle (288 hours), all coatings showed slow growth rate of the Al-oxide scale and spinels. Accelerated hot corrosion occurred during the 6th to 10th cycles. Since the surface Al-oxide scale was not effectively resistant against the hot corrosion, internal oxidation/nitridation of $\mathrm{Al}$ and oxidation along splats' interfaces took place in the coatings. The coating parts which were Al-depleted near the surface were further oxidized to form spinels.

The coatings containing Ru or Ir got thicker Al-oxide scales and larger amount of spinels than the coating without $\mathrm{Ru}$ and Ir. Such observed difference in the hot corrosion resistance, however, seemed to be related to the coating quality (porosity, intersplat oxidation, surface roughness, etc.) rather than due to the addition of this small amount of Ru or Ir. Based on the microstructure and chemical composition analyses, $\mathrm{Ru}$ and Ir neither were active in the hot corrosion process nor formed any detrimental oxides or phases inside the coating or at the coating surface. Those two elements were mainly observed to stay in the coating matrix, especially in the $\beta$ phase, or, if in some isolated coating fragments near the coating surface, would be slightly solve in spinels.

\section{Paper VII: Hot corrosion of MCrAlY coatings in sulphate and $\mathrm{SO}_{2}$ environment at $900{ }^{\circ} \mathrm{C}$ : is $\mathrm{SO}_{2}$ necessarily bad?}

Three types of hot corrosion testing were carried out on MCrAlY coatings at $900{ }^{\circ} \mathrm{C}$ : with salt deposition (SD), with salt deposition and $500 \mathrm{ppm} \mathrm{SO} \mathrm{SO}_{2}$ in air (SS), and with $500 \mathrm{ppm} \mathrm{SO}_{2}$ in air (SA). Two MCrAlY coatings was studied: one with a high Al content (10 wt.\% Al, 15 wt.\% Cr), namely coating $A$, and the other with a low $\mathrm{Al}$ content (7.5 wt.\% Al, 28 wt.\% $\mathrm{Cr}$ ), namely coating $B$. The temperature and time regime of the hot corrosions was the same as shown in Paper VI. The salt environment was about 20 to $30 \mu \mathrm{g} /\left(\mathrm{cm}^{2} \mathrm{~h}\right)(0.8 \mathrm{Na}, 0.2 \mathrm{~K})_{2} \mathrm{SO}_{4}$. XRD was used to identify the corrosion products formed at the coating surface. Furthermore, some specific peaks in the XRD spectra were used to quantitatively measure the amount of the corrosion products, e.g. alumina and spinels.

The results showed that the corrosion performance of the coatings was coating-composition and corrosion-condition dependent.

In the SD condition, coatings were attacked mainly due to the basic fluxing of alumina scale. Coating $A$ performed a better resistance than Coating $B$, due to its higher ability to support the growth and healing of the alumina scale. The difference became even larger in the SS condition, with very little attack observed on coating $A$ but heavy corrosion on Coating $B$ on which a nondense oxide layer of plate-like chromia formed above a fluxed Al-oxide scale. The chromia plates were formed probably through the oxidation of Cr-sulfides formed in the coating near the surface. On both Coating $A$ and Coating $B$, the SA condition gave little hot-corrosion attack.

The basic fluxing of the alumina scale was a reaction between alumina and $\mathrm{Na}_{2} \mathrm{O}$. By increasing the $\mathrm{SO}_{2}$ partial pressure in the atmosphere, the activity of $\mathrm{Na}_{2} \mathrm{O}$ decreased, resulting in a decrease of the fluxing degree of the alumina scale. That could be the reason for the limited attack observed on the high-Al content coating (i.e. Coating A) in the SS condition. The increase of the 
$\mathrm{SO}_{2}$ partial pressure in the molten sulphate, however, would also increase the risk of sulphidation. The sulphidation attack occurred in the low-Al content coating (i.e. Coating B). Cr-sulfides massively formed in this coating which had a low Al content and therefore failed to quickly form and maintain a protective alumina scale to hinder the inward diffusion of sulfur in the SS condition. 


\section{Bibliography}

[1] J.R. Davis, Heat-Resistant Materials, ASM International, Member/Customer Service Center, Materials Park, OH 44073-0002, USA, 1997.

[2] J.R. Nicholls, Advances in Coating Design for High Performance Gas Turbines, MRS Bull 28 (2003) 659-670.

[3] http://www.energy.siemens.com,

[4] R.C. Reed, The Superalloys Fundamentals and Applications, Cambridge University Press, New York, 2006.

[5] C.G. Levi, Emerging materials and processes for thermal barrier systems, Current Opinion in Solid State and Materials Science 8 (2004) 77-91.

[6] S. Bose, High Temperature Coatings, Butterworth-Heinemann, Oxford, 2007.

[7] W.G. Sloof and T.J. Nijdam, On the high-temperature oxidation of MCrAlY coatings, Int. J. Mater. Rsych. 100 (2009) 1318-1330.

[8] J.R. Nicholls, Designing oxidation-resistant coatings, JOM-J. Min. Met. Mat. S. 52 (2000) 2835 .

[9] S. Pahlavanyali, A. Sabour, M. Hirbod, The hot corrosion behaviour of HVOF sprayed MCrAlX coatings under Na2SO4 (+NaCl) salt films, Mater. Corros. 54 (2003) 687-693.

[10] B.M. Warnes, Improved aluminide/MCrAlX coating systems for super alloys using CVD low activity aluminizing, Surface and Coatings Technology 163 (2003) 106-111.

[11] D. Stöver and C. Funke, Directions of the development of thermal barrier coatings in energy applications, J.Mater.Process.Technol. 92-93 (1999) 195-202.

[12] A. Lasalmonie and J.L. Strudel, Influence of Grain Size on the Mechanical Behaviour of Some High Strength Materials, J.Mater.Sci. 21 (1986) 1837-1852.

[13] J. Sato, T. Omori, K. Oikawa, I. Ohnuma, R. Kainuma, K. Ishida, Cobalt-base hightemperature alloys, Science 312 (2006) 90-91.

[14] F.T. Furillo, J.M. Davidson, J.K. Tien, L.A. Jackman, The Effects of Grain Boundary Carbides on the Creep and Back Stress of a Nickel--Base Superalloy, Mater.Sci.Eng. 39 (1979) 267-273.

[15] C.T. Sims, N.S. Stoloff, W.C. Hagel, Superalloys II--High Temperature Materials for Aerospace and Industrial Power, xx $+615,16$ x $23 \mathrm{~cm}$, Illustrated, pounds sterling 63.75 (1987)

[16] T.J. Garosshen and G.P. McCarthy, Low Temperature Carbide Precipitation in a Nickel Base Superalloy, Metall.Trans.A 16A (1985) 1213-1223.

[17] S. Tin and T.M. Pollock, Phase instabilities and carbon additions in single-crystal nickelbase superalloys, Materials Science and Engineering: A 348 (2003) 111-121.

[18] J.M. Larson, Carbide Morphology in P/M IN-792, Metall.Trans.A 7A (1976) 1497-1502.

[19] T.N. Rhys-Jones, Coatings for blade and vane applications in gas turbines, Corros. Sci. 29 (1989) 623-646. 
[20] M.J. Pomeroy, Coatings for gas turbine materials and long term stability issues, Mater. Des. 26 (2005) 223-231.

[21] H.J. Grabke, Oxidation of NiAl and FeAl, Intermetallics 7 (1999) 1153-1158.

[22] J.G. Smeggil, Some comments on the role of yttrium in protective oxide scale adherence, Mater. Sci. Eng. 87 (1987) 261-265.

[23] J.T. DeMasi-Marcin and D.K. Gupta, Protective Coatings in the Gas Turbine Engine, Surf. Coat. Technol. 68/69 (1994) 1-9.

[24] H.E. Evans and M.P. Taylor, Oxidation of high-temperature coatings, Proceedings of the Institution of Mechanical Engineers G, Journal of Aerospace Engineering 220 (2006) 1-10.

[25] N. Czech, F. Schmitz, W. Stamm, Thermal mechanical fatigue behavior of advanced overlay coatings, Mater. Manuf. Process. 10 (1995) 1021-1035.

[26] B. Gudmundsson and B.E. Jacobson, Yttrium oxides in vacuum-plasma-sprayed CoNiCrAlY coatings, Thin Solid Films 173 (1989) 99-107.

[27] N.P. Padture, M. Gell, E.H. Jordan, Thermal barrier coatings for gas-turbine engine applications, Science 296 (2002) 280-284.

[28] R. Vaßen, M.O. Jarligo, T. Steinke, D.E. Mack, D. Stöver, Overview on advanced thermal barrier coatings, Surface and Coatings Technology 205 (2010) 938-942.

[29] H. Hindam and D.P. Whittle, Microstructure, adhesion and growth kinetics of protective scales on metals and alloys, Oxid. Met. 18 (1982) 245-284.

[30] T.J. Nijdam, L.P.H. Jeurgens, J.H. Chen, W.G. Sloof, On the microstructure of the initial oxide grown by controlled annealing and oxidation on a NiCoCrAlY bond coating, Oxidation Metals. 64 (2005) 355-377.

[31] V. Swamy, H.J. Seifert, F. Aldinger, Thermodynamic properties of Y2O3 phases and the yttrium-oxygen phase diagram, J.Alloys Compounds 269 (1998) 201-207.

[32] H. El Kadiri, R. Molins, Y. Bienvenu, M.F. Horstemeyer, Abnormal high growth rates of metastable aluminas on FeCrAl alloys, Oxid. Met. 64 (2005) 63-97.

[33] P. Puetz, X. Huang, R.S. Lima, Q. Yang, L. Zhao, Characterization of transient oxide formation on CoNiCrAlY after heat treatment in vacuum and air, Surf. Coat. Tech. 205 (2010) 647-657.

[34] W. Brandl, H.J. Grabke, D. Toma, J. Krüger, The oxidation behaviour of sprayed MCrAlY coatings, Surf. Coat. Technol. 86-87 (1996) 41-47.

[35] C.S. Giggins and F.S. Pettit, OXIDATION OF NI-CR-AL ALLOYS BETWEEN 1000 AND 1200 C, J.Electrochem.Soc. 118 (1971) 1782-1790.

[36] W.R. Chen, X. Wu, B.R. Marple, P.C. Patnaik, Oxidation and crack nucleation/growth in an air-plasma-sprayed thermal barrier coating with NiCrAlY bond coat, Surface and Coatings Technology 197 (2005) 109-115.

[37] J. Allen Haynes, E. Douglas Rigney, M.K. Ferber, W.D. Porter, Oxidation and degradation of a plasma-sprayed thermal barrier coating system, Surface and Coatings Technology 86-87, Part 1 (1996) 102-108.

[38] D.P. Moon, Role of Reactive Elements in Alloy Protection, Mater. Sci. Tech. 5 (1989) 754764.

[39] N. Birks, G.H. Meier, F.S. Pettit, Introduction to the high-temperature oxidation of metals, Cambridge University Press, UK, 2006.

[40] J.W. Hutchinson, M.Y. He, A.G. Evans, The influence of imperfections on the nucleation and propagation of buckling driven delaminations, J.Mech.Phys.Solids 48 (2000) 709-734. 
[41] A. Reddy, D.B. Hovis, A.H. Heuer, A.P. Paulikas, B.W. Veal, In Situ Study of OxidationInduced Growth Strains In a Model NiCrAlY Bond-Coat Alloy, Oxidation Metals 67 (2007) 153177.

[42] J.K. Tien and F.S. Pettit, Mechanism of oxide adherence on Fe-25Cr-4Al (Y or Sc) alloys, Metall. Mater. Tran. B 3 (1972) 1587-1599.

[43] J.G. Smeggil, A.W. Funkenbusch, N.S. Bornstein, A Relationship between Indigenous Impurity Elements and Protective Oxide Scale Adherence Characteristics, Metall. Trans. A. 17A (1986) 923-932.

[44] B.A. Pint, Optimization of reactive-element additions to improve oxidation performance of alumina-forming alloys, J. Am. Ceram. Soc. 86 (2003) 686-695.

[45] G.R. Wallwork and A.Z. Hed, Some limiting factors in the use of alloys at high temperatures, Oxid. Met. 3 (1971) 171-184.

[46] R. Anton, J. Birkner, N. Czech, W. Stamm, Degradation of Advanced MCrAlY Coatings by Oxidation and Interdiffusion, Trans Tech Publications Ltd., Materials Science Forum (Switzerland). 369-372 (2000) 719-726.

[47] E.Y. Lee, D.M. Chartier, R.R. Biederman, R.D.J. Sisson, Modelling the Microstructural Evolution and Degradation of M--Cr--Al--Y Coatings During High Temperature Oxidation, Surf.Coat.Technol. 32 (1987) 19-39.

[48] T. Beck, M. Biaas, P. Bednarz, L. Singheiser, K. Bobzin, N. Bagcivan, D. Parkot, T. Kashko, J. Petkovic, B. Hallstedt, S. Nemna, S.M. Jochen, Modeling of coating process, phase changes, and damage of plasma sprayed thermal barrier coatings on ni-base superalloys, Adv. Eng. Mater. 12 (2010) 110-126.

[49] D. Renusch, M. Schorr, M. Schutze, The role that bond coat depletion of aluminum has on the lifetime of APS-TBC under oxidizing conditions, Materials and Corrosion 59 (2008) 547-555. [50] N. Eliaz, G. Shemesh, R.M. Latanision, Hot corrosion in gas turbine components, Eng. Failure Anal. 9 (2002) 31-43.

[51] S. Kamal, R. Jayaganthan, S. Prakash, Hot Corrosion Studies of Detonation-Gun-Sprayed $\mathrm{NiCrAlY}+0.4$ wt.\% $\mathrm{CeO}_{2}$ Coated Superalloys in Molten Salt Environment, J. Mater. Eng. Perform. (2010)

[52] S. Krämer, J. Yang, C.G. Levi, C.A. Johnson, Thermochemical interaction of thermal barrier coatings with molten $\mathrm{CaO}-\mathrm{MgO}-\mathrm{A} 12 \mathrm{O} 3-\mathrm{SiO} 2$ (CMAS) deposits, J Am Ceram Soc 89 (2006) 3167-3175.

[53] R.A. Rapp, Hot Corrosion of Materials: A Fluxing Mechanism? Corros. Sci. 44 (2002) 209221.

[54] N. Bornstein and W. Allen, The Chemistry of Sulfidation Corrosion-Revisited, Mater. Sci. Forum. 251 (1997) 127-134.

[55] G.W. Goward, Progress in coatings for gas turbine airfoils, Surf. Coat. Technol. 108-109 (1998) 73-79.

[56] I. Gurrappa, Hot corrosion of protective coatings, Mater. Manuf. Process. 15 (2000) 761-773.

[57] J. Goebel and F. Pettit, Na2SO4-induced accelerated oxidation (hot corrosion) of nickel, Metall. Trans. 1 (1970) 1943-1954.

[58] J. Goebel, F. Pettit, G. Goward, Mechanisms for the hot corrosion of nickel-base alloys, Metall. Trans. 4 (1973) 261-278.

[59] R.A. Rapp, Chemistry and Electrochemistry of Hot Corrosion of Metals, Mater. Sci. Eng. 87 (1987) 319-327.

[60] C. Leyens, I. Wright, B. Pint, Effect of experimental procedures on the cyclic, hot-corrosion behavior of NiCoCrAlY-type bondcoat alloys, Oxid. Met. 54 (2000) 255-276. 
[61] C. Leyens, I.G. Wright, B.A. Pint, Hot corrosion of an EB-PVD thermal-barrier coating system at 950 deg C, Oxid. Met. 54 (2000) 401-424.

[62] Q.M. Wang, Y.N. Wu, P.L. Ke, H.T. Cao, J. Gong, C. Sun, L.S. Wen, Hot corrosion behavior of AIP NiCoCrAlY(SiB) coatings on nickel base superalloys, Surf. Coat. Technol. 186 (2004) 389-397.

[63] S.J. Geng, F.H. Wang, S.L. Zhu, W. Wu, Hot-corrosion resistance of a sputtered K38G nanocrystalline coating in molten sulfate at 900 C, Oxid. Met. 57 (2002) 549-557.

[64] V. Deodeshmukh, N. Mu, B. Li, B. Gleeson, Hot corrosion and oxidation behavior of a novel Pt + Hf-modified $\gamma^{\prime}$-Ni3Al $+\gamma$-Ni-based coating, Surf. Coat. Technol. 201 (2006) 38363840 .

[65] X. Ren and F. Wang, High-temperature oxidation and hot-corrosion behavior of a sputtered NiCrAlY coating with and without aluminizing, Surf. Coat. Technol. 201 (2006) 30-37.

[66] A.K. Misra, Studies on the hot corrosion of a nickel-base superalloy, Udimet 700, Oxid. Met. 25 (1986) 129-161.

[67] A. Misra, Mechanism of Na2 SO 4-Induced Corrosion of Molybdenum Containing NickelBase Superalloys at High Temperatures II. Corrosion in Atmospheres, J. Electrochem. Soc. 133 (1986) 1038-1042.

[68] K. Schneider and H.W. Grünling, Mechanical aspects of high temperature coatings, Thin Solid Films 107 (1983) 395-416.

[69] R. Lowrie and D.H. Boone, Composite coatings of CoCrAlY plus platinum, Thin Solid Films 45 (1977) 491-498.

[70] M. Alam, D. Chatterjee, S. Kamat, V. Jayaram, D. Das, Evaluation of ductile-brittle transition temperature (DBTT) of aluminide bond coats by micro-tensile test method, Mater. Sci. Eng. A 527 (2010) 7147-7150.

[71] T.K. Chaki, A.K. Singh, K. Sadananda, Effects of CoCrAlY coating on microstructural stability and creep behavior of a nickel-base superalloy, Thin Solid Films 168 (1989) 207-220.

[72] A. Sato, Y. Aoki, M. Arai, H. Harada, Effect of Aluminide Coating on Creep Properties of Ni-Base Single Crystal Superalloys, Journal of the Japan Institute of Metals 71 (2007) 320-325.

[73] H.J. Kolkman, Creep, Fatigue and Their Interaction in Coated and Uncoated Rene 80, Mater.Sci.Eng. 89 (1987) 81-91.

[74] M.G. Hebsur and R.V. Miner, Stress Rupture and Creep Behavior of a Low Pressure Plasma-Sprayed NiCoCrAlY Coating Alloy in Air and Vacuum, Thin Solid Films 147 (1987) 143-152.

[75] K. Aning and J.K. Tien, Creep and stress rupture behavior of a wrought nickel-base superalloy in air and vacuum, Materials Science and Engineering 43 (1980) 23-33.

[76] S. Suresh, Fatigue of materials, Cambridge university press, 1998.

[77] A. Strang and E. Lang, High Temperature Alloys for Gas Turbines 1982, Liege, Belgium, 46 Oct.1982; Liege; Belgium; 4-6 Oct.1982 (1982) 469.

[78] M. Okazaki, High-temperature strength of Ni-base superalloy coatings, Science and Technology of Advanced Materials 2 (2001) 357-366.

[79] K. Schneider, H. von Arnim, H.W. Grünling, Influence of coatings and hot corrosion on the fatigue behaviour of nickel-based superalloys, Thin Solid Films 84 (1981) 29-36.

[80] K. SCHNEIDER, G. GNIRSS, B. TRUECK, G.V. ARNIM, Mechanisms of High Cycle Fatigue of Cast Nickel Base Alloys, High Temperature Alloys for Gas Turbines 1982; Liege; Belgium; 4-6 Oct. 1982. (1982)

[81] W. Betz, Assessment of Protective Coatings to Combat Hot Gas Corrosion on Gas-Turbine Blades, Z.Werkstofftech., May 1976, 7, (5), 161-166 (1976) 
[82] G. Nover, C.H.J. Raub, H. Speckhardt, Fatigue Resistance of Hard-Chromed and NickelPlated Rotary Bending Specimens with Reference to Internal Stresses in the Coating, Metalloberflache 34 (1980) 169-173.

[83] K. Yuan, R. Lin Peng, X. Li, S. Johansson, Influence of Precracked Diffusion Coating of PtModified Aluminide on HCF Fracture Mechanism of IN 792 Nickel-Based Superalloy, Applied Mechanics and Materials 148-149 (2011) 24-29.

[84] Y.H. Zhang, P.J. Withers, M.D. Fox, D.M. Knowles, Damage mechanisms of coated systems under thermomechanical fatigue, Materials Science and Technology (UK) 15 (1999) 1031-1036.

[85] E. Tzimas, H. Müllejans, S.D. Peteves, J. Bressers, W. Stamm, Failure of thermal barrier coating systems under cyclic thermomechanical loading, Acta Materialia 48 (2000) 4699-4707.

[86] E. Vacchieri, A. Costa, E. Poggio, S. Corcoruto, Effect of NiCoCrAlY+Re coatings on TMF behaviour of first and second generation single crystal Ni based superalloys, Energy Materials: Materials Science \& Engineering for Energy Systems 4 (2012) 189-197.

[87] J.E. Morral, C. Jin, A. Engstr, J. Ågren, Three types of planar boundaries in multiphase diffusion couples, Scr.Mater. 34 (1996) 1661-1666.

[88] T. Gomez-Acebo, B. Navarcorena, F. Castro, Interdiffusion in multiphase, Al-Co-Cr-Ni-Ti diffusion couples, Journal of Phase Equilibria and Diffusion 25 (2004) 237-251.

[89] A. Engstrom, J.E. Morral, J. Agren, Computer simulations of Ni-Cr-Al multiphase diffusion couples, Acta Materialia (USA) 45 (1997) 1189-1199.

[90] Y. Itoh and M. Tamura, Reaction diffusion behaviors for interface between Ni-based super alloys and vacuum plasma sprayed MCrAlY coatings, Journal of engineering for gas turbines and power 121 (1999) 476-483.

[91] M.P. Taylor, W.M. Pragnell, H.E. Evans, Evidence for the formation of Al-rich reservoir phases resulting from interdiffusion between MCrAlY coating and Ni-based substrate, Mater. Sci. Forum 461-464 (2004) 239.

[92] S.M. Jiang, H.Q. Li, J. Ma, C.Z. Xu, J. Gong, C. Sun, High temperature corrosion behaviour of a gradient NiCoCrAlYSi coating II: Oxidation and hot corrosion, Corros. Sci. 52 (2010) 23162322.

[93] C.E. Campbell, W.J. Boettinger, U.R. Kattner, Development of a diffusion mobility database for Ni-base superalloys, Acta mater. 50 (2002) 775-792.

[94] K. Yuan, R. Eriksson, R. Lin Peng, X. Li, S. Johansson, Y. Wang, Modeling of microstructural evolution and lifetime prediction of MCrAlY coatings on nickel based superalloys during high temperature oxidation, Surf. Coat. Technol. 232 (2013) 204-215.

[95] K. Yuan, R. Eriksson, R. Lin Peng, X. Li, S. Johansson, Y. Wang, MCrAlY coating design based on oxidation-diffusion modelling. Part I: Microstructural evolution, Surf. Coat. Technol. 254 (2014) 79-96.

[96] N. Czech, F. Schmitz, W. Stamm, Microstructural analysis of the role of rhenium in advanced MCrAlY coatings, Surf. Coat. Technol. 76-77 (1995) 28-33.

[97] N. Czech, F. Schmitz, W. Stamm, Improvement of MCrAlY coatings by addition of rhenium, Surf. Coat. Technol. 68-69 (1994) 17-21.

[98] J.A. Nesbitt and R.W. Heckel, Modeling Degradation and Failure of Ni--Cr--Al Overlay Coatings, Thin Solid Films 119 (1984) 281-290.

[99] T.J. Nijdam, L.P.H. Jeurgens, W.G. Sloof, Modelling the thermal oxidation of ternary alloys-compositional changes in the alloy and the development of oxide phases, Acta Materialia 51 (2003) 5295-5307. 
[100] J. Agren, Numerical Treatment of Diffusional Reactions in Multicomponent Alloys, J. Phys. Chem. Solids 43 (1982) 385-391.

[101] T.J. Nijdam and W.G. Sloof, Modelling of composition and phase changes in multiphase alloys due to growth of an oxide layer, Acta Mater. 56 (2008) 4972-4983.

[102] R. Eriksson, K. Yuan, X. Li, R. Lin Peng, MCrAlY coating design based on oxidationdiffusion modelling. Part II: Lifing aspects, Surf. Coat. Technol. 253 (2014) 27-37.

[103] K. Yuan, R. Lin Peng, X. Li, S. Johansson, Y. Wang, Simulation of Oxidation-NitridationInduced Microstructural Degradation in a Cracked Ni-Based Superalloy at High Temperature, MATEC Web of Conferences. 14 (2014) 16004-p.1-p.6.

[104] W. Brandl, D. Toma, J. Krüger, H.J. Grabke, G. Matthäus, The oxidation behaviour of HVOF thermal-sprayed MCrAlY coatings, Surf. Coat. Technol. 94-95 (1997) 21-26.

[105] H. Peng, H. Guo, R. Yao, J. He, S. Gong, Improved oxidation resistance and diffusion barrier behaviors of gradient oxide dispersed NiCoCrAlY coatings on superalloy, Vacuum 85 (2010) 627-633.

[106] A. Fossati, M. Di Ferdinando, A. Lavacchi, U. Bardi, C. Giolli, A. Scrivani, Improvement of the isothermal oxidation resistance of CoNiCrAlY coating sprayed by High Velocity Oxygen Fuel, Surf. Coat. Technol. 204 (2010) 3723-3728.

[107] H.E. Evans and M.P. Taylor, Diffusion cells and chemical failure of MCrAlY bond coats in thermal-barrier coating systems, Oxidation of Metals (USA) 55 (2001) 17-34. 


\section{Part II}

Appended Papers 



\section{Appended Papers}

The articles associated with this thesis have been removed for copyright reasons. For more details about these see:

http://urn.kb.se/resolve?urn=urn:nbn:se:liu:diva-111119 